\title{
대학에서의 팀기반 학습 설계모형 개발연구
}

장선영 (張善英)

이정주 $(\text { 李挺株 })^{* *}$

\section{논문 요약}

본 연구의 목적은 대학에서의 팀기반 학습을 위한 설계모형을 개발하는데 있다. 연구의 목적을 달성하기 위해 본 연구는 크게 3 단계로 진행되었다. 먼저 팀기반 학습 및 설계모형과 관련된 문헌분석 결과를 기반으로 1 차 모형을 개발하였다. 1 차 모형에 대한 개선점을 확인하기 위해 4 인의 전문가 검토와 초보 교수설계자 3 인의 모형 에 대한 사용성 평가를 실시하였다. 마지막으로, 전문가 검토 및 사용성 평가 결과를 반영하여 최종모형을 개발 하였다. 개발된 모형은 팀기반 학습 설계 적합성 분석, 학습자 분석, 팀 구성, 환경분석, 환경 설계, 과제설계, 과제 개발, 평가도구 개발, 수업전략 개발, 평가 체제 개발, 강의계획서 개발, 형성평가 실시, 팀기반 학습 실행, 총괄평가 실행 단계로 구성된다. 그리고 모형의 각 단계에 대한 설계활동 및 지침을 제시함으로써 대학에서 팀기 반학습을 설계하고 실행하고자 하는 교수자에게 실제적인 정보를 제공하였다. 최종 모형은 7인의 전문가 타당화 를 거쳐 타당성을 검증받았으며, 마지막으로 본 연구에 대한 논의점과 시사점이 제안되었다.

주요어 : 대학교육, 팀기반 학습, 설계모형, 모형개발

\section{I. 서론}

현대사회가 지식기반 사회로 변모함에 따라 21세기가 요구하는 인재에게 필요한 능력으로 문 제해결능력, 비판적사고력, 의사소통능력, 창의력이 주목받고 있다(Trilling, \& Fadel, 2009). 특 히 우리나라 학습자들이 우선적으로 증진해야 할 능력으로 문제해결력, 협력, 창의적 사고능력,

* 교신저자, 청강문화산업대학교, 조교수

** 중앙대학교, 교육학과 석사과정 
의사소통, 자기주도력 등이 보고되고 있다(허희옥, 임규연, 서정희, 김영애, 2011). 이러한 능력 들은 초·중·고등학교 보다 대학에서 더 중요하고(Boud \& Falchikov, 2006), 현재의 대학들은 기 존의 교육 방식에서 학습자가 창의적으로 문제를 해결하여 지식을 창출할 수 있도록 하는 발전 된 교육 방식으로의 전환이 필요하다(Boud \& Falchikov, 2006; Ndebele \& Maphosa, 2013; Snowball \& Boughey, 2012; ).

이러한 시대적 요구에 대응하기 위하여 교육에 있어서도 지식 전달보다는 지식의 응용력에 초점을 맞추어 가면서 팀을 이루어 학습하는 집단학습이 지속적으로 연구되어 오고 있다 (Parmelee \& Michaelsen, 2010). 특히 대학들은 유의미한 학습, 비판적 사고, 문제 해결력 등을 통한 지식의 창출을 목적으로 하는 교육을 위해 많은 노력을 기울이고 있다(박수홍, 2007; 황철 일, 이성호, 2011; Chin\&Chia, 2004). 하지만 현재 대학에서 행해지는 수업의 형태는 중고등학교 의 소규모 강의보다는 한 명의 교수자가 대규모의 학생들을 강의하는 대형 강의가 대다수를 차 지하고 있으며(김은경, 조주은, 정의철, 2009; 유병민, 허균, 2004), 이러한 대형 강의에서 학생 개개인을 모두 학습에 참여시켜 학생의 유의미한 학습이나 능동적인 학습을 이끄는 것은 많은 노력을 요하는 도전적인 일이다(Cuseo, 2007; Ndebele \& Maphosa, 2013). 2013년도 당시 50명 이상의 대규모 수업은 국 ·공립 대학 전체 강좌의 $13.6 \%$ 인 57,785 개, 사립대학 전체 강좌의 $14.8 \%$ 인 221,932개의 강좌가 운영되고 있는데 이러한 대규모 수업에서 소집단으로 협동하며 학 습하는 학습자 중심 교육을 실행하기란 사실상 어렵다(한국대학교육협의회, 2013).

대학에서 대형 강의를 해야 하는 상황적 요소를 고려하여, 학습자 개개인을 학습에 참여시키 는 동시에 시대가 요구하는 학습자의 핵심역량을 향상시키는 교육 방식으로 팀기반 학습 (Team-based Learning: TBL)이 주목받고 있다(조형정, 이영민, 2008; 하채영, 이수영, 2014). 팀기 반 학습은 학습 팀이 최대한의 학습 성과를 이루어 내도록 하며, 그 팀들이 학습 과업에 의미 있는 역할을 할 수 있는 기회를 제공하는 교수법이다(Michaelsen, Knight \& Fink, 2009). 팀기반 학습은 개별학습과 수업 내에서의 팀 학습을 접목시켜 진행되는 대형 강의에 적합한 수업 방식 으로, 학생들이 학습된 개념을 활용하여 스스로 문제를 해결하는 자기 주도적 학습을 가능하게 한다(박귀화, 최창휴, 전양빈, 박국양, 박철현, 2012; 조형정, 이영민, 2008; Andersen, Strumpel, Fensom, \& Andrews. 2011; Fujikura, et al., 2013; Michaelsen \& Sweet, 2008b).

팀기반 학습은 그 절차가 복잡하여 적용하기 어렵고, 실행 시에도 매 단계마다 지속적인 교수 자의 피드백이 제공되기 때문에 교수자는 많은 시간과 노력을 기울여야 하는데( Dana, 2007), 이 를 위해서는 사전에 체계적인 과정을 거쳐 수업이 설계될 필요가 있다. 팀기반 학습 모형대로 수업을 충실하게 실행한다고 해도, 팀활동에 불규칙적으로 참여하는 학습자 또는 팀활동에 참여 하는 것을 포기하는 학습자들이 발생하기 때문이다(Weiner, Plass, and Marz, 2009). Haidet와 그의 동료들(2012)도 팀기반 학습에 관한 연구들이 증가하고 있고 그 가치가 인정받고 있음에도 
불구하고, 교수학습 환경, 학습자, 내용의 다양성으로 인해 적용하기 위해 연구되어야 할 부분이 많다고 언급한다. 이뿐만 아니라, 학습자의 참여 및 협력, 긍정적인 팀분위기 형성을 위해 준비 하고, 점검하고 지원하기 위해서는 매우 세심한 계획이 필요하다고 강조한다. Michaelsen과 Richards(2005)는 팀기반 학습이 단일 강좌에서부터 전체 코스까지 다양하게 적용할 수 있기 때 문에, 팀기반학습에 대한 이해가 쉽지 않다고 강조한다. 이영민과 그의 동료들(2011b) 역시 기존 의 팀기반 학습 모형의 타당성에 관한 연구는 미흡한 실정임을 제시한 바 있다.

팀기반 학습 실천의 어려움에 대한 선행연구들은 대학에서 교수자들이 성공적으로 팀기반 학습을 운영하기 위해서는 교수자들이 팀기반 학습을 준비하고 운영하고 평가하는 일련의 과정 을 안내하는 설계모형이 필요함을 시사한다. 설계모형이란 설계하고자 하는 것과 관련된 요소와 절차로 구성된 모형이다(Jang, 2011). 설계모형은 복잡한 현상을 단순화하는 모형의 특성을 포함 하고 있으며(Wisely, 1994), 설계의 시작부터 끝까지의 과정 및 절차, 각 단계별 설계활동까지 포함하고 있다(강정찬, 2009; Lesh, \& Doerr, 2003). 대학의 교육상황 및 특성을 반영한 팀기반 학습 설계모형이 개발된다면, 팀기반 학습을 처음 적용하고자 하는 교수자들에게 유용한 정보를 제공할 수 있을 것이다. 뿐만 아니라, 대학에 소속된 다양한 교육지원 기관들이나 센터들이 팀기 반 학습 설계모형을 활용하여 팀기반 학습 관련 연구 및 지원프로젝트를 수행할 수 있다.

그러나 팀기반 학습에 관한 선행연구들은 대부분이 그 효과성을 입증하는 연구들(예: 이영민, 남정권, 조형정, 이수영, 2011a; McInerney, \& Fink, 2003)이 주를 이루고 있다. 팀기반 학습의 운영에 관해 지금까지 이루어진 연구들과 팀기반 학습 모형에 관한 연구들은 대부분 팀기반 학 습을 실제로 수업에 적용하는데 있어 유의미한 정보를 제시하는데 그치고 있는 실정이다.

또한, 팀기반 학습 설계모형과 관련된 연구도 소수 존재하기는 하지만, 이러한 연구 역시 의. 약학 분야에서의 이루어진 연구이거나, 최신 테크놀로지 등을 적용한 모형 개발과 관련된 연구 들이 대부분이다. 이러한 연구들은 일반적인 대학의 대형 강의에서 팀기반 학습의 적용을 위해 교수나 교수설계자가 참고하기에 어려운 한계점이 있다. 이에 본 연구에서는 대학에서 교수자들 이 효과적이고 효율적으로 팀기반 학습을 하고자 할 때, 수업 설계 및 운영과 관련된 전 과정을 안내하는 설계모형을 개발하고자 한다. 


\section{․ 이론적 배경}

\section{1. 팀기반 학습의 개념 및 절차}

팀기반 학습은 1970년대 Michaelsen에 의해 처음으로 제안되었는데(Michaelsen et al, 2009), 팀기반 학습이란 팀원들이 공동의 목표를 달성하기 위해 팀원들끼리 비전공유 및 상호작용을 통해 기존에 배웠던 지식을 실제 과제에 연결시키면서 과제를 해결함으로써 학습을 증진시키도 록 안내하는 교수법이다(노영숙, 류언나, 최동원, 백선숙, 김상숙, 2012).

팀기반 학습을 효과적으로 실행하기 위해서는 팀기반 학습의 각 단계를 진행해야 한다. 팀기 반 학습은 크게 세단계로 진행된다(조형정, 이영민, 2008; Parmelee, Michaelsen, Cook, \& Hudes, 2012). [그림1]에서도 제시되어 있듯이, 팀기반 학습의 첫 번째 단계는 본격적인 수업에 들어가기에 앞서서 학습자가 사전에 학습할 내용에 대한 선행학습을 하는 단계이다. 이 단계에 서 학습자들은 교사가 제시한 학습 내용에 관계된 읽기자료를 사전에 읽고 학습하여 수업 준비 를 한다. 사전 학습이 끝나면 학습된 내용에 대해 개인평가와 팀 평가를 시행한다. 그리고 학습 이해에 문제가 있는 부분은 팀과 교사간의 소통을 통해 해결하고 점검한다. 준비 활동이 끝난 후 두 번째 단계에서는 학습된 지식과 관련된 실제 상황에 일어날 법 한 과제가 제시된다. 여기 서 학습자들은 자신들이 미리 학습한 선행 지식을 기반으로 팀 구성원간의 상호작용을 통해서 논의하고 추론하고 적용하여 해결책을 도출하는 과정을 거친다. 이 단계는 실질적인 과제 해결 학습을 위한 과정으로 학습자의 다양한 역량이 요구된다. 이렇게 각 구성원들이 제안한 추론을 기반으로 각 팀만의 답변을 만들고 교수는 그 과정에서 피드백을 제공할 수 있다. 이 과정에서 팀 구성원들은 자신이 학습한 개념들을 활성화시켜 더 높은 수준을 학습할 수 있게 되며, 팀 구 성원들 간에 응집력이 발생한다(Michaelsen et al., 2009). 이러한 과제 해결단계가 끝나고 나면, 마지막으로 팀 별 산출물에 대한 결과물을 평가하고, 동료 평가를 하여 성적을 합산한다. 동료 평가로 인해 학습자들은 도덕적 책무성을 갖게 되고, 서로간의 장, 단점을 파악할 수 있게 된다. 이러한 평가 방법은 학습자들에게 성숙된 변화의 기회를 제공한다(Parmelee et al., 2012). 
딤 기반 학습의 3 단계 활용

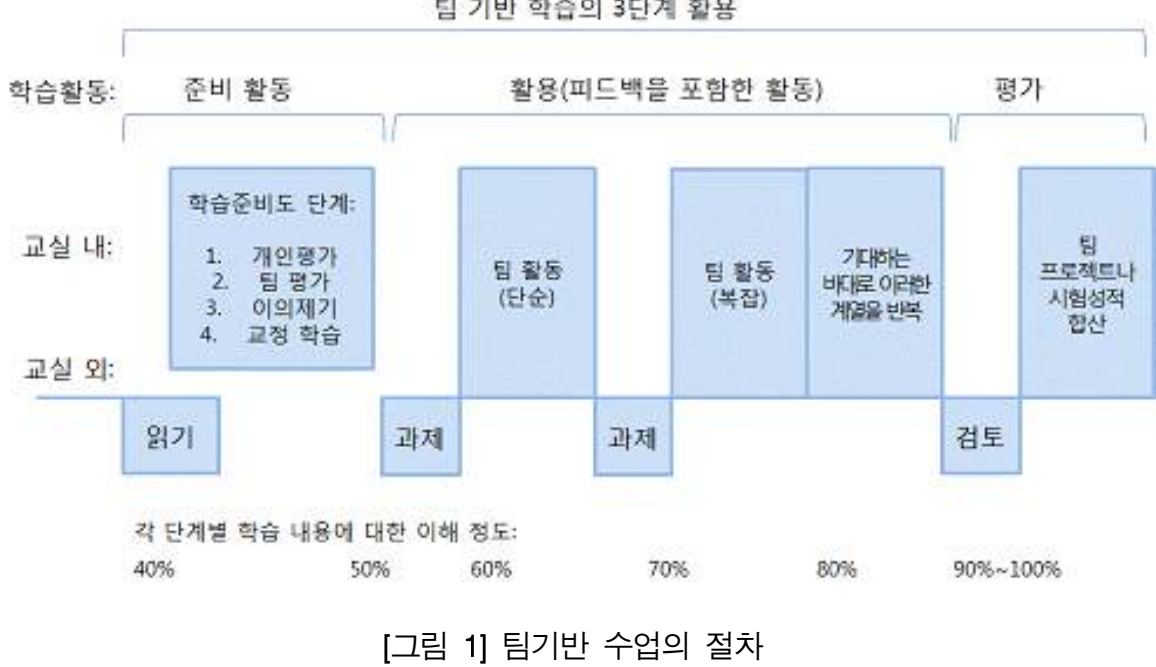

팀기반 학습의 효과성을 향상시키기 위해서 교수자가 해야 할 주요 활동은 다음과 같다. 첫째, 교수자는 교육과정을 개발하고 운영하는 역할을 수행해야 한다. 즉, 교수자는 학습자들이 팀활 동을 통해 습득해야 할 학습내용을 규명하고, 팀활동을 하기 위한 전략을 수립하며, 수행정도를 평가하는 역할을 해야 한다(조아라, 2010). 둘째, 교수자는 팀원들 모두가 서로 과제해결에 기여 할 수 있도록 팀구성을 해야 하며(Cannon-Bowers, Tannenbaum, Salas, \& Volpe, 1995 ), 팀원들 이 서로 신뢰하면서 공동으로 과제를 수행할 수 있도록 세심한 주의를 기울여야 한다(Watson, Michaelsen \& Sharp, 1991). 팀활동에서 학습자 개개인이 자신이 속한 팀에 대해 긍정적인 인식 을 하면, 이는 곧 팀활동 결과에도 긍정적인 영향을 미치기 때문이다(Widen-Wulff \& Gimman, 2004).

셋째, 교수자는 학습자들의 학습활동을 점검하며 필요시 즉각적인 피드백을 자주 제공해야 한다(심미자, 2009).

이러한 교수자의 역할을 성공적으로 수행하기 위해서는 다양한 방안이 모색되어야 한다. 이 를 위한 다양한 방안 중 하나가 팀기반 학습을 설계하는 일련의 과정을 안내하는 모형이 될 수 있다.

\section{2. 팀기반 학습의 효과성}

현재까지 팀기반 학습에 관한 선행연구 중 팀기반 학습의 효과성을 증명한 연구는 매우 많다. 특히 팀기반 학습에 관한 효과성 연구는 대부분 실제 수업에 팀기반 학습을 적용한 사례연구(예: 노영숙 외, 2012; 박인숙, 김동기, 2009; 이영민 외, 2011a; 이영민, 남정권, 조형정, 이수영, 2011b; 
하채연, 이수영, 2014; 한수정, 2013; Clair \& Chihara, 2012; Dana, 2007; Pogge, 2013)를 중심으 로 이루어져 왔다. 팀기반 학습 사례연구들은 팀기반 학습을 실제 수업에 적용시켜 학습자의 만 족도와 학습 성과, 인지 성과 등을 분석하여 그 효과성을 증명하는 연구들이 대부분이다.

팀기반 학습의 효과성에 대한 선행연구를 탐색한 결과 효과성은 크게 학업적 성과, 정서적 성과, 행동적 성과로 구분된다. 학업적 성과 측면에서 팀기반 학습을 연구한 문헌들의 경우, 학 업 성취도, 학습 지속력, 의사소통 능력, 과제 이해도 측면에서 성과를 다루고 있다(노영숙 외, 2012; 박인숙, 김동기, 2009; Dana, 2007; Pogge, 2013). 정서적 측면에서의 팀기반 학습을 연구 한 문헌들의 경우, 만족도, 효과성 인식, 학습 동기, 자신감, 흥미에 대한 효과를 다루고 있다(이 영민 외, 9011b; 한혜승 외, 2007; Andersen et al., 2011). 만족도는 팀기반 학습으로 이루어진 수업 방식에 대한 선호도를 나타내며 효과성은 선호도와는 관계없이 팀기반 학습이 효과가 있 다고 인식하는지에 대한 학습자의 주관적인 판단을 나타낸다. 행동적 성과 측면에서 팀기반 학 습을 연구한 문헌들의 경우, 학습 태도, 자발적 학습, 리더십, 수업 참여도, 협력성에서의 효과를 다루고 있다(박인숙, 김동기, 2009; 한수정, 2013; Clair\&Chihara, 2012). 학습 태도는 학습자가 학습에 대한 태도가 긍정적인지 부정적인지를 나타낸다. 지금까지 보고된 연구들을 통해, 팀기 반 학습의 효과성은 여러 측면에서 그 성과가 입증되었다고 볼 수 있다.

\section{3. 팀기반 학습 설계모형에 관한 선행연구}

팀기반 학습 설계와 관련된 선행연구는 활발히 이루어지지 않은 실정이다. 팀기반 학습 설계 와 직접적인 관련은 없더라도, 설계모형을 개발하는데 있어 유의미한 정보를 주는 선행연구들을 살펴보면 다음과 같다. 첫째, 팀기반 학습을 구성하는 요소와 관련된 선행연구이다. 이는 팀기 반 학습 설계모형을 개발하는데 있어 고려해야 할 요소들을 파악하는데 유의미한 정보를 제공 한다. 선행 연구를 통해 도출된 팀기반 학습 설계를 위해 고려해야 할 구성요소는 분석, 설계, 개발, 평가 단계로 나누어 볼 수 있다. 먼저 분석 단계에서 요구분석을 시작으로 과제분석, 환경 분석, 학습자 분석을 실시하여 해당 수업이 팀기반 학습을 실행하기에 적합한지 분석한다. 설계 단계에서는 분석한 내용을 바탕으로 환경설계, 수업 내용 설계, 팀 구성, 평가 체계 설계, 강의 계획서 설계 등 효율적인 팀기반 학습을 실행하는데 필요한 요소들을 설계한다. 개발 단계에서 는 설계된 내용을 바탕으로 읽기자료, 학습 준비도 평가 문항, 응용과제, 요약강의(mini lecture), 평가 도구를 개발하고, 최종 결과물에 대한 평가와 수정이 이루어진다. 마지막으로 평가단계에 서는 팀기반 학습을 실행한 후 수업을 수정하는 활동이 요구된다. 이상에서 내용을 종합하여 정 리한 결과는 다음 <표1>과 같다. 
<표 1> 팀기반 학습 설계모형의 구성요소

\begin{tabular}{|c|c|c|c|c|c|c|c|c|}
\hline & $\begin{array}{l}\text { 팀기반 햑습 } \\
\text { 설계모형의 } \\
\text { 구성요소 }\end{array}$ & $\begin{array}{l}\text { Michaelsen \& } \\
\text { Sweet } \\
\text { (2008a) }\end{array}$ & $\begin{array}{l}\text { 조이라 } \\
\text { (2008) }\end{array}$ & $\begin{array}{c}\text { 조형정, } \\
\text { 이영민(2008) }\end{array}$ & $\begin{array}{l}\text { Parmelee } \\
\text { et al., } \\
\text { (2012) }\end{array}$ & $\begin{array}{l}\text { Haidet et al., } \\
\qquad(2012)\end{array}$ & $\begin{array}{l}\text { Mennenga\&S } \\
\text { myer(2010) }\end{array}$ & $\begin{array}{l}\text { Dana, S. } \\
\text { W.(2007). }\end{array}$ \\
\hline \multirow[t]{3}{*}{ 분석 } & 요구분석 & & & $\begin{array}{c}\text { 학습 목표 } \\
\text { 수립 }\end{array}$ & $\begin{array}{c}\text { 학습 목표 } \\
\text { 수립 }\end{array}$ & & & $\begin{array}{l}\text { 수업 목표가 } \\
\text { 팀기반 } \\
\text { 학습으로 } \\
\text { 도달 } \\
\text { 가능한지 } \\
\text { 확인 }\end{array}$ \\
\hline & 환경분석 & & $\begin{array}{c}\text { 필요한 } \\
\text { 자원 점검 }\end{array}$ & $\begin{array}{c}\text { 학습 환경 } \\
\text { 분석 }\end{array}$ & & & & \\
\hline & 학습자 분석 & & & $\begin{array}{c}\text { 학습자 특성 } \\
\text { 분석 }\end{array}$ & $\begin{array}{c}\text { 학습자 } \\
\text { 분석(ex. } \\
\text { 선행지식) } \\
\end{array}$ & & & $\begin{array}{c}1 \text { 차시에 } \\
\text { 학습자 분석 } \\
\text { 실행 }\end{array}$ \\
\hline \multirow{6}{*}{ 설계 } & 환경설계 & $\begin{array}{l}\text { 조별 활동 } \\
\text { 가능한 } \\
\text { 환경마련 }\end{array}$ & & & & & & \\
\hline & $\begin{array}{c}\text { 수업내용 } \\
\text { 설계 }\end{array}$ & & & $\begin{array}{c}\text { 교과 내용 } \\
\text { 구성 }\end{array}$ & & & & $\begin{array}{c}\text { 수업 내용의 } \\
\text { 설계 }\end{array}$ \\
\hline & 과제설계 & $\begin{array}{c}\text { 수업 내용 } \\
\text { 구상 }\end{array}$ & & & & & & \\
\hline & 팀 구성 & $\begin{array}{c}\text { 구성원 간 } \\
\text { 이질적 } \\
\text { 팀 간 동질적 } \\
\text { 으로 팀 구성 }\end{array}$ & & & $\begin{array}{c}\text { 다양한 } \\
\text { 특징의 } \\
\text { 구성원의 팀 } \\
\text { 형성 }\end{array}$ & $\begin{array}{c}\text { 학습자의 } \\
\text { 수준을 } \\
\text { 고려한 팀 } \\
\text { 구성 }\end{array}$ & $\begin{array}{c}\text { 팀 간 } \\
\text { 수준이 } \\
\text { 비슷하도록 } \\
\text { 구성 } \\
\end{array}$ & $\begin{array}{c}\text { 학습자 특성 } \\
\text { 고려한 팀 } \\
\text { 구성방안 } \\
\text { 설계 }\end{array}$ \\
\hline & $\begin{array}{c}\text { 평가 체계 } \\
\text { 설계 }\end{array}$ & $\begin{array}{c}\text { 팀 기여도를 } \\
\text { 반영한 } \\
\text { 성적체계 } \\
\text { 설계 }\end{array}$ & & $\begin{array}{c}\text { 개인/팀 평가 } \\
\text { 별 가중치 } \\
\text { 설계 }\end{array}$ & $\begin{array}{l}\text { 단계별 평가 } \\
\text { 가중치 설계 }\end{array}$ & $\begin{array}{c}\text { 평가 체계 } \\
\text { 설계 }\end{array}$ & & $\begin{array}{c}\text { 팀/개인별 } \\
\text { 평가 체계 } \\
\text { 설계 }\end{array}$ \\
\hline & $\begin{array}{c}\text { 동료평가체계 } \\
\text { 설계 }\end{array}$ & $\begin{array}{c}\text { 동료 } \\
\text { 평가체계 } \\
\text { 설계 } \\
\end{array}$ & & $\begin{array}{c}\text { 동료/팀원 간 } \\
\text { 평가 설계 }\end{array}$ & $\begin{array}{l}\text { 양적/질적 } \\
\text { 동료 평가 } \\
\text { 체계 설계 }\end{array}$ & & & $\begin{array}{c}\text { 팀 내 } \\
\text { 활동에 대한 } \\
\text { 동료 평가 }\end{array}$ \\
\hline \multirow{7}{*}{ 개발 } & $\begin{array}{c}\text { 읽기 자료 } \\
\text { 개발 }\end{array}$ & $\begin{array}{c}\text { 개념관련 } \\
\text { 읽기자료 } \\
\text { 개발 }\end{array}$ & & $\begin{array}{c}\text { 학습 자료 } \\
\text { 개발 }\end{array}$ & $\begin{array}{c}\text { 팀 ㅎㅘㅘ동의 } \\
\text { 스캐폴딩이 } \\
\text { 될 수 있는 } \\
\text { 준비 자료 } \\
\text { 마련 }\end{array}$ & $\begin{array}{c}\text { 학습 준비를 } \\
\text { 위한 } \\
\text { 읽기자료 } \\
\text { 개발 }\end{array}$ & $\begin{array}{c}\text { 주제 적합 } \\
\text { 읽기자료 } \\
\text { 개발 }\end{array}$ & $\begin{array}{l}\text { 기본 개넘을 } \\
\text { 명시한 } \\
\text { 읽기자료 } \\
\text { 개발 }\end{array}$ \\
\hline & $\begin{array}{l}\text { 학습준비도 } \\
\text { 평가문항 개발 }\end{array}$ & $\begin{array}{l}\text { 수업단위별로 } \\
\text { 문제를 개발 }\end{array}$ & & $\begin{array}{c}\text { 개인별, 팀별 } \\
\text { 점검 문제 } \\
\text { 개발 }\end{array}$ & $\begin{array}{c}\text { 개별/팀별 } \\
\text { 점검 문제 } \\
\text { 개발 }\end{array}$ & $\begin{array}{c}\text { 평가 문항 } \\
\text { 개발 }\end{array}$ & $\begin{array}{c}\text { 이해를 돕는 } \\
\text { 문항 개발 }\end{array}$ & $\begin{array}{c}\text { 이해도를 } \\
\text { 묻는 문항 } \\
\text { 개발 }\end{array}$ \\
\hline & 응용과제 개발 & $\begin{array}{c}\text { 팀원 간 상호 } \\
\text { 토론 촉진 } \\
\text { 과제 }\end{array}$ & & $\begin{array}{l}\text { 의사결정 } \\
\text { 과제 개발 }\end{array}$ & $\begin{array}{c}\text { 실제적 과제 } \\
\text { 개발 }\end{array}$ & $\begin{array}{c}\text { 고차원적 } \\
\text { 사고 유도 } \\
\text { 과제 }\end{array}$ & $\begin{array}{c}\text { 개념 } \\
\text { 응용과제 }\end{array}$ & $\begin{array}{l}\text { 복잡한 과제 } \\
\text { 상황 설정 }\end{array}$ \\
\hline & 강의 개발 & & $\begin{array}{c}\text { 학습내용 } \\
\text { 이해를 위한 } \\
\text { 강의 }\end{array}$ & & & & & \\
\hline & 평가도구 개발 & $\begin{array}{c}\text { 평가문항 } \\
\text { 개발 }\end{array}$ & & $\begin{array}{c}\text { 개인/팀별 } \\
\text { 학습 } \\
\text { 평가문항 } \\
\text { 개발 }\end{array}$ & $\begin{array}{c}\text { 평가 문항 } \\
\text { 개발 }\end{array}$ & & & \\
\hline & $\begin{array}{c}\text { 동료 평가도구 } \\
\text { 개발 }\end{array}$ & $\begin{array}{c}\text { 동료평가문항 } \\
\text { 개발 }\end{array}$ & & $\begin{array}{l}\text { 팀원 내, } \\
\text { 동료 } \\
\text { 평가문항 } \\
\text { 개발 }\end{array}$ & $\begin{array}{c}\text { ㅇㅑㅑ적/질적 } \\
\text { 평가문항 } \\
\text { 개발 }\end{array}$ & & & \\
\hline & $\begin{array}{c}\text { 강의계획서 } \\
\text { 설계 }\end{array}$ & $\begin{array}{c}\text { 수업내용강의 } \\
\text { 계획서에 } \\
\text { 명시 }\end{array}$ & & & & & & \\
\hline \multicolumn{2}{|c|}{ 평가 및 피드백 } & $\begin{array}{c}\text { 실행 후 평가 } \\
\text { 및 수정 }\end{array}$ & & & & & & $\begin{array}{c}\text { 실행 후 } \\
\text { 학습자의 } \\
\text { 평가, 반응 } \\
\text { 수렴 }\end{array}$ \\
\hline
\end{tabular}


둘째, 팀기반 학습 원리에 대한 개념적 연구(Hrynchak \& Batty, 2012; Michaelsen \& Sweet, $2008 \mathrm{~b}$ )이다. 팀기반 학습의 원리에 대한 개념적 연구들은 대체로 팀기반 학습의 개념과 팀기반 학습이 가지는 기본 원리, 팀기반 학습의 기반이 되는 학습이론 등을 제시하고 있다. 또한 팀기 반 학습의 일반적인 절차에 대한 세부사항을 기술하여 팀기반 학습 설계를 위해 교수설계자가 해야 할 설계관련 행동들에 대한 시사점을 제공한다.

셋째, 팀기반 학습의 운영을 위한 지침이나 적용을 위한 모형 개발 연구 (조아라, 2008; 이수영, 2013; Haidet, Levine, Parmelee, Crow, Kennedy, Kelly \& Richards, 2012; Loo, 2013)이다. Haidet 과 그의 동료들(2012)은 학생과 교사의 관점에서 팀기반 학습을 진행하기 위한 단계별 절차에 따 른 행동을 기술하고 있다. 즉, 팀기반 학습을 하는데 있어 수업 단계별로 학생, 교사가 해야 하는 행동과 주의사항에 대한 안내가 상세히 제공되고 있다. 조아라(2008)는 의학교육에서 팀기반 학습 을 효과적으로 활용하기 위한 팁을 제시하기 위한 연구를 진행하였는데 이 연구에서는 팀기반 학 습을 실행하기 위해 도움이 될 만한 원리와 팁을 제안하고 있다. 이밖에도, 스마트 기술을 반영하 여 팀기반 학습 모형을 개발한 연구도 수행되었다(이수영, 2013). 이 연구에서는 S-TBL 수업의 기 본이 되는 핵심 원리들을 제시하고, 그를 바탕으로 S-TBL 수업 진행 절차와 그 절차별 상황적 지 침을 제시하고 있다.. $\mathrm{LoO}(2013)$ 역시 팀기반 학습을 적용하기 위한 안내를 제시하고 있다.

이상에서 언급된 연구들은 설계모형을 도출하는데 일부 유의미한 정보를 제공한다. 하지만 팀기반 학습의 절차적인 부분보다는 팀기반 학습에 필요한 요소들과 적용 후 결과에 초점을 맞 추었기 때문에 일반적인 대학 수업에서 팀기반 학습 적용을 위해 교수자가 참고할 수 있는 안내 나 지침으로는 한계가 있다고 볼 수 있다.

\section{III. 연구방법}

본 연구는 설계, 개발, 평가 등의 절차를 안내하는 모형을 연구하는 개발연구에 속한다 (Richey, 1997). 모형을 개발하기 위해 본 연구에서는 팀기반 학습 설계모형을 개발하기 위해 관련 문헌 분석을 통해 팀기반 학습을 설계하는 데 필요한 단계들을 도출하고, 도출된 단계들을 포함한 설계모형을 개발한 후 내적 타당화 방법(전문가검토, 사용성평가, 전문가 타당화 방법)을 채택하였다. 전문가 검토는 모형을 보고 의견을 제안하는데 목적이 있으며, 사용성 평가는 직접 모형을 사용하여 수업을 설계함으로써 모형의 장점을 확인하거나 개선점을 도출하는 과정을 통 해 모형의 타당성을 검증하는데 목적이 있다. 전문가 타당화는 다양한 측면에서 모형을 검토함 으로써 최종 모형으로 확정할 정도로 타당한지 여부를 판단하는데 그 목적이 있다. 구체적인 팀기반 수업 설계모형의 개발 절차는 아래 <표 2>와 같다. 


\section{<표 2> 연구 절차}

\begin{tabular}{|c|c|c|c|}
\hline 단계 & 목적 & 세부단계 & 결과물 \\
\hline $\begin{array}{c}\text { 1차 모형 } \\
\text { 개발 }\end{array}$ & $\begin{array}{l}\text { 1차 팀기반 } \\
\text { 학습 } \\
\text { 설계모형 } \\
\text { 개발 }\end{array}$ & $\begin{array}{l}\text { - 팀기반 학습 실행 안내 및 사례 } \\
\text { 연구와 관련된 문헌 탐색 } \\
\text { - 대학 수업에 맞추어 팀기반 학습 } \\
\text { 구성요소 도출 } \\
\text { - 구성요소 단계별 지침 구체화 } \\
\text { - } 1 \text { 차 모형 설계 }\end{array}$ & $\begin{array}{l}\text { - 팀기반 학습의 구성 } \\
\text { 요소 } \\
\text { - 대학 수업에 맞춘 팀 } \\
\text { 기반 학습의 구성요소 } \\
\text { - 구체화된 } 1 \text { 차 설계모형 }\end{array}$ \\
\hline$\downarrow$ & $\downarrow$ & $\downarrow$ & \\
\hline $\begin{array}{l}\text { 전문가 } \\
\text { 검토 }\end{array}$ & $\begin{array}{l}1 \text { 차 모형에 } \\
\text { 대한 전문가 } \\
\text { 검토 }\end{array}$ & $\begin{array}{l}\text { - 전문가 } 4 \text { 인 대상 } \\
\text { - 설문지/인터뷰를 통해 모형의 구성 } \\
\text { 요소와 절차에 대한 전문가 검토 }\end{array}$ & - 전문가 검토 결과 \\
\hline$\downarrow$ & $\downarrow$ & $\downarrow$ & \\
\hline $\begin{array}{l}\text { 사용성 } \\
\text { 평가 }\end{array}$ & $\begin{array}{l}1 \text { 차 모형에 } \\
\text { 대한 사용성 } \\
\text { 평가 실시 }\end{array}$ & $\begin{array}{l}\text { - 초보 교수설계자 3인 대상 } \\
\text { - 설문과 인터뷰를 실시하여 모형의 } \\
\text { 사용성에 대한 평가 }\end{array}$ & - 사용성 평가 결과 \\
\hline$\downarrow$ & $\downarrow$ & $\downarrow$ & \\
\hline $\begin{array}{l}\text { 최종 } \\
\text { 모형 } \\
\text { 개발 }\end{array}$ & $\begin{array}{l}\text { 1차 모형 } \\
\text { 수정 }\end{array}$ & $\begin{array}{l}\text { - 전문가 검토와 사용성 평가 결과 } \\
\text { 를 기반으로 최종 모형 완성 }\end{array}$ & $\begin{array}{l}\text { - 최종 팀기반 학습 설 } \\
\text { 계모형 }\end{array}$ \\
\hline$\downarrow$ & $\downarrow$ & $\downarrow$ & \\
\hline $\begin{array}{l}\text { 모형 } \\
\text { 타당화 }\end{array}$ & $\begin{array}{l}\text { 최종 모형에 } \\
\text { 대한 전문가 } \\
\text { 타당화 실시 }\end{array}$ & $\begin{array}{l}\text { - 수정된 모형이 팀기반 학습 설계 } \\
\text { 의 절차와 내용을 잘 설명하고 있 } \\
\text { 는지에 대해 } 7 \text { 인의 설계 전문가 } \\
\text { 타당화 }\end{array}$ & - 전문가 타당화 결과 \\
\hline
\end{tabular}

\section{1차 모형 개발}

1 차 팀기반 학습 설계 모형을 개발하기 위해 설계모형 개발 연구를 위한 문헌분석에서 주로 제안되는 문헌탐색 기준을 활용하여 문헌분석을 실시하였다(나지현, 정현미, 2012; 임철일 외, 2013) . 즉, 팀기반 학습 설계의 모형 개발을 위해 설계 및 개발과정, 설계를 위한 구성요소들과 관련된 문헌을 선정하여 분석하였다. 1 차 모형을 개발하기 위해 최종적으로 선정된 23 편의 논문 (사례연구 10 편, 안내 및 개발연구 4 편, 개념 연구 9편)을 분석하여 각 문헌에서 제시한 팀기반 학 습 설계의 핵심이 될 수 있는 구성요소들을 비교하고 구성 요소별 상황적 지침을 살펴보았다. 문 헌들을 고찰할 때 팀기반 학습 설계의 기본 원리들과 교수자가 팀기반 학습 설계 시 겪었던 어려 움들을 고려하여 분석하였다. 이렇게 분석된 내용을 바탕으로 구성 요소들을 종합하고 특별히 팀 기반 학습을 대학 수업에 적용할 때 적합하도록 새로운 요소를 추가하거나 수정하여 최종 구성 
요소들을 도출하였다. 또 팀기반 학습을 실행한 사례에서 교수자가 제시한 어려움들을 충분히 보 안할 수 있도록 추가적인 상황적 지침을 도출하여 1차 설계모형을 완성하였다([그림 2 ] 참조).

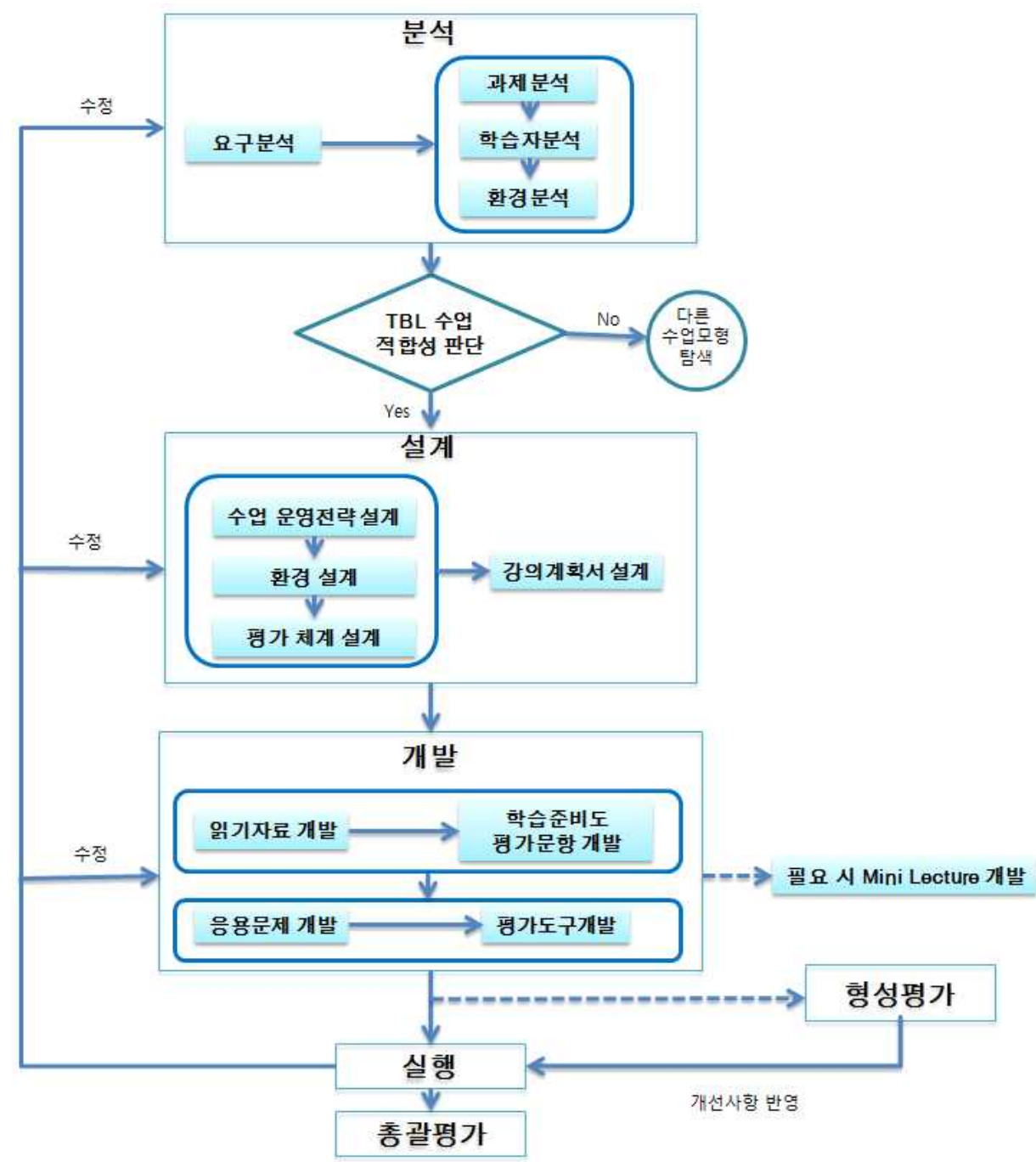

[그림 2] 대학에서의 팀기반학습 설계모형 (1차 모형)

이모형은 분석, 설계, 개발의 세 단계로 이루어진다. 먼저 요구분석을 통해 학습자들이 해당 강좌의 학습 목표에 도달하기 위해 $\mathrm{TBL}$ 수업이 적합한 지 파악한다. $\mathrm{TBL}$ 수업이 적합하다고 판단되면 과제분석, 학습자 분석, 환경 분석을 통해 수업설계를 위해 필요한 정보를 확보한 뒤 본 수업의 설계를 실행한다. 설계는 가장 먼저 수업 내용을 설계하고, 수업 내용에 맞도록 팀 구성 방안을 설계한다. 팀 구성 방안이 결정되면, 구성된 팀들이 활동하기에 적합하도록 수업 
환경을 설계하고, 마지막으로 학습 성과에 대한 평가체제를 설계한다. 수업에 필요한 모든 요소 가 설계되면, 그것을 바탕으로 학습자에게 수업에 대한 정보를 제공해줄 수 있도록 강의 계획서 를 설계한다. 개발 단계에서는 가장 먼저 수업 전 학습자에게 배포될 사전 읽기자료를 개발한 후 사전 수업 학습 준비도를 평가할 수 있는 사전 준비도 평가 문항을 개발한다. 개발된 읽기 자료를 바탕으로 문제 해결 능력을 기를 수 있는 효과적인 응용문제를 개발한 뒤 최종적으로 학습자의 학습 성과를 평가할 수 있는 평가 도구를 개발한다. 만약 교수자가 필요하다고 생각되 면 mini lecture를 개발하여 학습자에게 제공해줄 수 있다. 이 모든 과정이 끝나면 설계된 수업 을 바탕으로 시뮬레이션을 해 보고 학습자들이 제공한 피드백을 설계 내용에 반영하여 수정한 후 실행한다. 마지막은 형성평가 단계로 다시 전체 과정 및 개발된 도구들을 점검해보고 실행 후 학습자들의 반응을 반영하여 수정 보완한 후 최종적으로 수업 설계안을 완성한다.

\section{2. 전문가 검토}

개발된 최초의 모형에 대한 개선점을 확인하기 위하여 전문가 검토를 실행하였다. 전문가 검 토를 실시한 이유는 이 방법이 모형의 전체적인 구조와 절차, 요소들을 검토하는데 매우 효율적 인 접근법으로 모형의 내적 타당도를 검토하기 위해 가장 일반적으로 활용되는 방법이기 때문 이다( Richey, 2005). 전문가 검토를 할 때에는 모형이 적용되는 맥락에 영향을 미칠 수 있는 요 소들을 중점적으로 검토해야 한다. 이를 위해 수업설계 및 모형개발 전문가 2인, 팀기반 학습 전문가 2 인 총 4 인을 대상으로 개발된 모형의 구성요소와 절차에 대해 개방형 질문으로 인터뷰 를 실시하였다. 본 단계에 참여한 전문가들은 모두 대학에서의 강의경력이 7년 이상이며, 대형 강의와 팀기반 수업을 모두 진행한 경험이 있다.

전문가 검토를 통해 모형의 요소들이 빠짐없이 포함되었는지, 요소들의 절차가 적절하게 배 열되었는지, 학습의 전이와 효과에 영향을 미치는 환경적인 요소가 충분히 고려되었는지에 대한 전문가 의견을 수집하였다. 또 팀기반 학습을 대학 수업에 적용시키기 위해 고려해야하는 요소 가 충분히 언급되었는지, 맥락을 고려할 때 추가적으로 언급해야 하는 사항이 있는지에 대해 인 터뷰를 실시하였다. 인터뷰는 30분 1시간 정도로 진행하였으며 인터뷰의 녹음본을 전사하여 그 내용을 분석하였다. 인터뷰의 내용 분석 결과와 반영 사항에 대해 정리한 내용은 아래<표 $3>$ 와 같다. 


\begin{tabular}{|c|c|}
\hline 전문가 의견 & 반영 결과 \\
\hline $\begin{array}{l}\text { 팀기반 학습 설계모형만의 특성이 드러나지 않음. 모형 자 } \\
\text { 체에서 팀기반 학습의 특성인 팀 활동 과제에 대한 설계, } \\
\text { 개발부분이 표현되어야 할 것으로 보임 }\end{array}$ & $\begin{array}{l}\text { 모형에서 팀 활동을 위한 기본 과제, } \\
\text { 심화 과제에 대한 설계와 개발단계를 } \\
\text { 추가 }\end{array}$ \\
\hline 강의계획서 개발은 모든 수업준비가 끝나고 이루어져야함 & $\begin{array}{l}\text { 과제 개발단계 후 강의 계획서 개발 } \\
\text { 단계를 배치 }\end{array}$ \\
\hline $\begin{array}{l}\text { 모든 분석이 끝난 후 모든 설계가 이루어지는 것 보다 환경 } \\
\text { 분석이 끝나고 환경 설계, 학습자 분석이 끝나고 팀 구성, } \\
\text { 과제 분석이 끝나고 과제 설계를 하는 방식이 더 분석 결과 } \\
\text { 를 제대로 반영할 수 있을 것으로 보임 }\end{array}$ & $\begin{array}{l}\text { 환경 분석 후 환경 설계, 학습자 분 } \\
\text { 석 후 팀 구성을 각각 같은 수준의 } \\
\text { 단계에 배치 }\end{array}$ \\
\hline $\begin{array}{l}\text { 대학 강의 특성상 학습자 분석이 } 1 \text { 차시 수업 전에 이루어지 } \\
\text { 는 것은 힘듬. 최종 수강생이 정해진 뒤에 학습자 분석이 } \\
\text { 이루어질 수 있기 때문에 이 부분을 보완할 수 있는 추가적 } \\
\text { 인 안내 필요가 있음. }\end{array}$ & 학습자 분석 단계에 추가적으로 기술 \\
\hline $\begin{array}{l}\text { 강의계획서는 설계가 아닌 개발된 결과물이므로 강의계획서 } \\
\text { 개발로 수정할 필요가 있음. }\end{array}$ & $\begin{array}{l}\text { 강의계획서 설계 } \rightarrow \text { 강의계획서 개발 } \\
\text { 로 수정 }\end{array}$ \\
\hline $\begin{array}{l}\text { 팀기반 학습의 특성이 잘 드러나도록 모형에서 각 단계마다 } \\
\text { 간결한 활동 지침을 제시해주는 것이 좋을 것 같음. }\end{array}$ & $\begin{array}{l}\text { 각 단계별로 간결한 활동지침이 드러 } \\
\text { 나도록 수정 }\end{array}$ \\
\hline $\begin{array}{l}\text { 모든 수업이 끝난 후 수업에 대한 총괄 평가 시 강의 평가 } \\
\text { 내용을 반영할 수 있음. }\end{array}$ & 총괄 평가 내용에 추가적으로 기술 \\
\hline
\end{tabular}

\section{3. 사용성 평가}

사용성 평가는 모형이 수업 내에서 효과적이고 효율적으로 사용될 수 있는 지에 대한 여부를 평가하는 것이다(Richey \& Klein, 2007). 이 단계에서는 실제 교수 설계자가 하고자 하는 과목을 선정하여 해당 모형의 절차대로 수업을 설계해보고 모형의 문제점이나 모형을 활용했을 때 어 려운 점, 개선점 등을 제안한다(Richey, 2005). 본 연구에서 개발된 모형에 대한 최종 사용자는 대학에서의 강의 경험이 3년 미만인 초보 교수설계자이다. 따라서 교육학을 전공으로 하는 박사 과정에 있고, 대학에서의 강의 경력이 있으며, 수업을 설계한 경험이 비교적 적은 교수 설계 초 보자 3인을 대상으로 사용성 평가를 실시하였다. 사용성 평가를 위해 연구진이 초보설계자에게 팀기반학습 설계모형에 대해 충분히 설명하고, 초보설계자의 질문에 응답하는 과정을 거쳤다. 그 다음 초보설계자가 대학에서 교육하게 될 과목 한 개를 선정하여 팀기반학습 설계모형을 활 용하여 수업을 설계하였다. 사용성 평가 과정은 약 2주 정도가 소요되었으며, 설계하는 과정에 서 이메일이나 전화, 또는 면담을 통해 교수설계자의 질문에 응답하였다.

설계 초보자 3 인은 본 모형을 참고하여 서로 다른 수업 주제를 가지고 팀기반 수업을 설계하 
였으며, 설계가 끝난 뒤 본 모형이 초보자가 쉽게 사용할 수 있는지, 대부분의 수업 환경에서 모두 효율적으로 활용 가능한지, 본 모형이 다양한 수업 전략과 수업 내용을 수용할 수 있는 지, 수정 보완해야 할 부분이 있는지 등을 검토했다. 모형 사용성 평가문항은 Traecy (2001)가 사용 했던 사용성 평가문항을 본 연구에 맞게 수정·보완하여 사용하였다. 사용성 평가문항은 모형의 각 단계별 지침들이 명확히 설명되었는지 묻는 부분과, 모형 전체에 대한 사용성에 대해 묻는 부분으로 구별된다. 단계별 지침에 대한 사용성 평가의 결과는 아래의 <표 $4>$ 와 같다.

<표 4> 단계별 지침에 대한 사용성 평가

\begin{tabular}{ccccccc}
\hline \multirow{2}{*}{ 단계별 지침에 대한 설명의 명확성 } & \multicolumn{3}{c}{ 사용자 반응 } & \multirow{2}{*}{ 평균 } & \multirow{2}{*}{ 표준 } \\
\cline { 2 - 4 } & $\mathrm{A}$ & $\mathrm{B}$ & $\mathrm{C}$ & & 편차 \\
\hline 팀기반 학습 설계 적합성 분석 & 3 & 3 & 4 & 3.33 & 0.58 \\
\hline 학습자 분석 & 4 & 3 & 4 & 3.67 & 0.58 \\
\hline 팀 구성 & 4 & 2 & 4 & 3.33 & 1.15 \\
\hline 환경 분석 & 5 & 2 & 4 & 3.67 & 1.53 \\
\hline 환경 설계 & 4 & 4 & 4 & 4.00 & 0.00 \\
\hline 과제 설계 & 4 & 2 & 5 & 3.67 & 1.53 \\
\hline 과제 개발 & 4 & 2 & 5 & 3.67 & 1.53 \\
\hline 평가도구 개발 & 4 & 2 & 4 & 3.33 & 1.15 \\
\hline 수업전략 개발 & 5 & 4 & 5 & 4.67 & 0.58 \\
\hline 평가체제 개발 & 4 & 4 & 4 & 4.00 & 0.00 \\
\hline 강의계획서 개발 & 4 & 4 & 4 & 4.00 & 0.00 \\
\hline 형성평가 실시 & 3 & 4 & 4 & 3.67 & 0.58 \\
\hline 팀기반 학습 실행 & 4 & 4 & 3 & 3.67 & 0.58 \\
\hline 총괄평가 실시 & 4 & 3 & 4 & 3.67 & 0.58 \\
\hline
\end{tabular}

각 단계 별 지침에 대한 사용성 평가 결과는 팀기반 학습 적합성 분석, 팀 구성, 평가 체제 설계 단계의 지침이 전반적으로 낮은 점수를 받았다. 이 점을 반영하여 2차 모형에서는 초보 설 계자도 쉽게 이해할 수 있도록 단계별 지침에 대한 설명을 자세히 기술하였다. 특히 팀기반 학습 적합성 분석단계와 팀 구성 단계에서는 이해하기 어려울 수 있는 내용들에 대해 예시를 추가하 여 이해하기 쉽도록 하였다. 모형에 대한 사용성 평가 결과(<표 6>)에서는 각 단계에 대한 예시 자료의 충분성과 모형에 포함된 수업 전략의 도움 정도에서 전반적으로 낮은 점수를 받았다. 따 라서 각 단계 별 관념적일 수 있는 설명에 대해 충분한 예시를 추가적으로 제시하였고, 수업 전 략도 설계자들의 반응을 반영하여 충분히 목표를 달성할 수 있을 정도로 자세하고 전략적으로 기술하였다. 
<표 5> 모형에 대한 사용성 평가

\begin{tabular}{|c|c|c|c|c|c|}
\hline \multirow{2}{*}{ 문항 } & \multicolumn{3}{|c|}{ 사용자 반응 } & \multirow{2}{*}{ 평균 } & \multirow{2}{*}{$\begin{array}{l}\text { 표준 } \\
\text { 편차 }\end{array}$} \\
\hline & A & $\mathrm{B}$ & $\mathrm{C}$ & & \\
\hline 본 모형은 어디서 어떻게 시작해야 할지가 명확히 이해된다. & 5 & 4 & 5 & 4.67 & 0.58 \\
\hline $\begin{array}{l}\text { 모형의 각 단계에 대한 예시자료들은 모형을 수월하게 사용 } \\
\text { 하는 데에 도움을 준다. }\end{array}$ & 3 & 2 & 5 & 3.33 & 1.53 \\
\hline 본 모형은 선생님들이 사용하기 쉽다(명확하다) & 4 & 5 & 3 & 4.00 & 1.00 \\
\hline $\begin{array}{l}\text { 본 모형에 포함된 수업전략을 활용하는 것은 수업의 본래 목 } \\
\text { 적을 달성하는 데에 도움을 준다. }\end{array}$ & 4 & 3 & 3 & 3.33 & 0.58 \\
\hline $\begin{array}{l}\text { 본 모형을 활용하는 것과 본 수업의 전개가 전체적으로 조화 } \\
\text { 롭게 이루어졌다. }\end{array}$ & 3 & 4 & 4 & 3.67 & 0.58 \\
\hline
\end{tabular}

이밖에 초보 설계자들이 제시된 문항 외에 추가적으로 제언한 부분들의 결과는 <표 6>과 같다.

<표 6> 설계자 의견 반영 결과

\begin{tabular}{|c|c|c|}
\hline 단계 & 사용자 의견 & 반영 결과 \\
\hline $\begin{array}{l}\text { 학습자 } \\
\text { 분석 }\end{array}$ & $\begin{array}{l}\text { - 학습자의 지식수준을 객관적으로 평가할 수 있는 } \\
\text { 데이터, 객관적인 지표 제시 필요 } \\
\text { - 예) report 결과, 실습 점수 }\end{array}$ & - 예시로 제시 \\
\hline 팀 구성 & $\begin{array}{l}\text { - 팀 구성 시 필수적으로 고려해야 할 사항에 대한 } \\
\text { 예시 필요 (ex. 지식수준, 흥미도 등등) } \\
\text { - 이질적/동질적 팀 구성방법에 대한 상세한 설명 필요 }\end{array}$ & $\begin{array}{l}\text { - 예시로 제시 } \\
\text { - 팀 구성 방법 자세히 } \\
\text { 기술 }\end{array}$ \\
\hline $\begin{array}{l}\text { 환경 } \\
\text { 설계 }\end{array}$ & $\begin{array}{l}\text { - 학습자가 더욱 효과적으로 팀 활동을 할 수 있도 } \\
\text { 록 자리배치 유형에 대한 예시 제공 }\end{array}$ & $\begin{array}{l}\text { - 팀 배치에 대한 예시 } \\
\text { 제시 }\end{array}$ \\
\hline $\begin{array}{l}\text { 총괄평가 } \\
\text { 실시 }\end{array}$ & $\begin{array}{l}\text { - 읽기자료를 통해 제시된 내용이 실제로 팀기반 } \\
\text { 활동을 하는데 필요한 지식 및 사항으로 제시되 } \\
\text { 었는지에 대한 평가도 필요함. }\end{array}$ & $\begin{array}{l}\text { - 총괄평가 시 고려할 부 } \\
\text { 분으로 기술하여 반영 }\end{array}$ \\
\hline 기타 & $\begin{array}{l}\text { - 교수학습 맥락에서 효과적이고 효율적인 팀 운영 } \\
\text { 에 대한 가이드 필요 }\end{array}$ & $\begin{array}{l}\text { - 팀 운영에 대한 교수자 } \\
\text { 로 역할을 기술 }\end{array}$ \\
\hline
\end{tabular}

\section{4. 모형 타당화}

전문가 검토와 모형사용성 평가 결과를 반영하여 최종적으로 완성된 모형이 팀기반 학습 설 계의 절차와 내용을 정확히 반영하고 있는지 확인하기 위해 교수설계 및 모형전문가 7인(교육학 박사 6인, 경영학 박사 1인)을 대상으로 타당화를 실시하였다. 이 단계에 참여한 전문가는 대학 교수로써 팀별 활동이 있는 수업 및 대형 강의 경력이 7년 이상이며 교수설계 및 모형개발 경험 이 풍부하다.

타당화 검사도구는 모형에 대한 타당화를 실시한 선행연구에서 사용되었던 도구(예: 나일주, 
정현미, 2001; Jang, 2011)를 본 연구의 목적에 맞게 수정, 보완하여 사용하였다. 타당화 도구는 개발된 모형에 대한 내용 타당도, 이해도, 설명력, 유용성, 그리고 보편성에 대해 5점 Likert 척도 에 표시하는 방식의 문항으로 구성되어 있다.

타당화 결과를 해석하기 위해 응답 일치도(IRA: Inter- rater Agreement)와 내용타당도 지수 (CVI: Content Validity Index)를 활용하였다(진성희, 2009; Rubio et al., 2003). 평가자간 일치도 (IRA)는 타당화에 참여한 응답자들이 각 문항에 한 응답에 대한 일치도를 나타낸 값으로, 이 값 이 0.8 이상이면 타당하다고 판단할 수 있다. 내용타당도 지수(Content Validity Index: CVI)는 각각의 타당화 문항에 대해 타당하다고 평가한 응답의 일치정도를 나타낸 값이다. 이 값은 타당 하다고 표시한 응답자의 수를 전체 전문가의 수로 나눈 값이며, 이 값이 0.8 이상일 경우 응답자 들의 평가가 신뢰롭다고 해석할 수 있다. 모형에 대한 타당화 결과는 소수점 반올림을 허용한 소수점 1 자리로 제시하였으며, 그 결과는 아래 <표 7>과 같다.

<표 7> 타당화 결과

\begin{tabular}{|c|c|c|c|c|c|c|c|c|c|c|}
\hline & \multirow{2}{*}{ 질문 } & \multicolumn{7}{|c|}{ 응답자 } & \multirow{2}{*}{ CVI } & \multirow{2}{*}{ IRA } \\
\hline & & A & B & $\mathrm{C}$ & $\mathrm{D}$ & $E$ & $\mathrm{G}$ & $\mathrm{H}$ & & \\
\hline \multirow{4}{*}{ 타당도 } & $\begin{array}{l}\text { 제시된 TBL 모형은 필요한 모든 단계들이 빠짐 } \\
\text { 없이 제시되었다 }\end{array}$ & 5 & 5 & 5 & 5 & 4 & 4 & 5 & $8 / 8=1$ & \multirow{9}{*}{$\begin{array}{c}8 / 9= \\
0.9\end{array}$} \\
\hline & $\begin{array}{l}\text { 제시된 TBL 모형을 구성하는 단계들은 그 순서 } \\
\text { 가 적절하게 배열되었다. }\end{array}$ & 5 & 4 & 5 & 5 & 5 & 4 & 5 & $8 / 8=1$ & \\
\hline & $\begin{array}{l}\text { 제시된 TBL 모형은 대학수업에서 적용하기 위해 } \\
\text { 고려해야 할 요소들을 빠짐없이 포함되어 있다. }\end{array}$ & 5 & 5 & 5 & 5 & 4 & 4 & 5 & $8 / 8=1$ & \\
\hline & $\begin{array}{l}\text { 제시된 TBL 모형은 교수 설계자에게 단계별로 } \\
\text { 실행해야 할 정확한 지침이 포함되어 있다. }\end{array}$ & 5 & 5 & 5 & 5 & 5 & 4 & 5 & $8 / 8=0.9$ & \\
\hline 이해도 & $\begin{array}{l}\text { 제시된 } \mathrm{TBL} \text { 모형은 대학에서의 팀기반 학습 설 } \\
\text { 계를 위한 활동과 절차들에 대해 사용자가 이해 } \\
\text { 하기 쉽도록 표현되어 있다. }\end{array}$ & 5 & 5 & 4 & 4 & 4 & 4 & 4 & $8 / 8=1$ & \\
\hline \multirow[b]{2}{*}{ 설명력 } & $\begin{array}{l}\text { 제시된 TBL 모형은 대학에서의 팀기반 학습 설 } \\
\text { 계과정이 한 눈에 쉽게 파악되도록 표현되었다. }\end{array}$ & 5 & 5 & 4 & 5 & 4 & 4 & 5 & $8 / 8=1$ & \\
\hline & $\begin{array}{l}\text { 제시된 TBL 모형을 통해 학습자들의 협력학습과 } \\
\text { 유의미한 학습을 지원하기 위한 수업설계과정을 파 } \\
\text { 악할 수 있는 큰 그림을 그리는데 도움이 되었다. }\end{array}$ & 5 & 5 & 5 & 5 & 3 & 4 & 5 & $7 / 8=0.9$ & \\
\hline 유용성 & $\begin{array}{l}\text { TBL 모형은 대학수업 상황에서 팀기반 학습을 } \\
\text { 설계하는데 유용하게 활용될 수 있다. }\end{array}$ & 5 & 5 & 5 & 4 & 4 & 4 & 5 & $8 / 8=1$ & \\
\hline 보편성 & $\begin{array}{l}\text { 제시된 모형을 사용하여 팀기반 학습과 공통점이 } \\
\text { 많은 수업을 설계할 수 있다. }\end{array}$ & 5 & 5 & 5 & 4 & 4 & 4 & 5 & $8 / 8=1$ & \\
\hline
\end{tabular}

타당화 결과를 보면 문항별 내용타당도 지수(CVI)와 평가자간 일치도(IRA) 모두 0.9 이상으로 나타났으며, 이는 본 연구를 통해 도출된 최종 모형이 타당함을 의미한다. 


\section{IV. 연구결과}

본 연구에서 최종적으로 개발된 팀기반 학습 설계 모형은 크게 분석, 자료의 설계와 개발, 평 가의 세 단계로 이루어진다([그림 3]참조). 팀기반 학습 설계모형의 각 활동별 구체적인 설명은 아래와 같다.

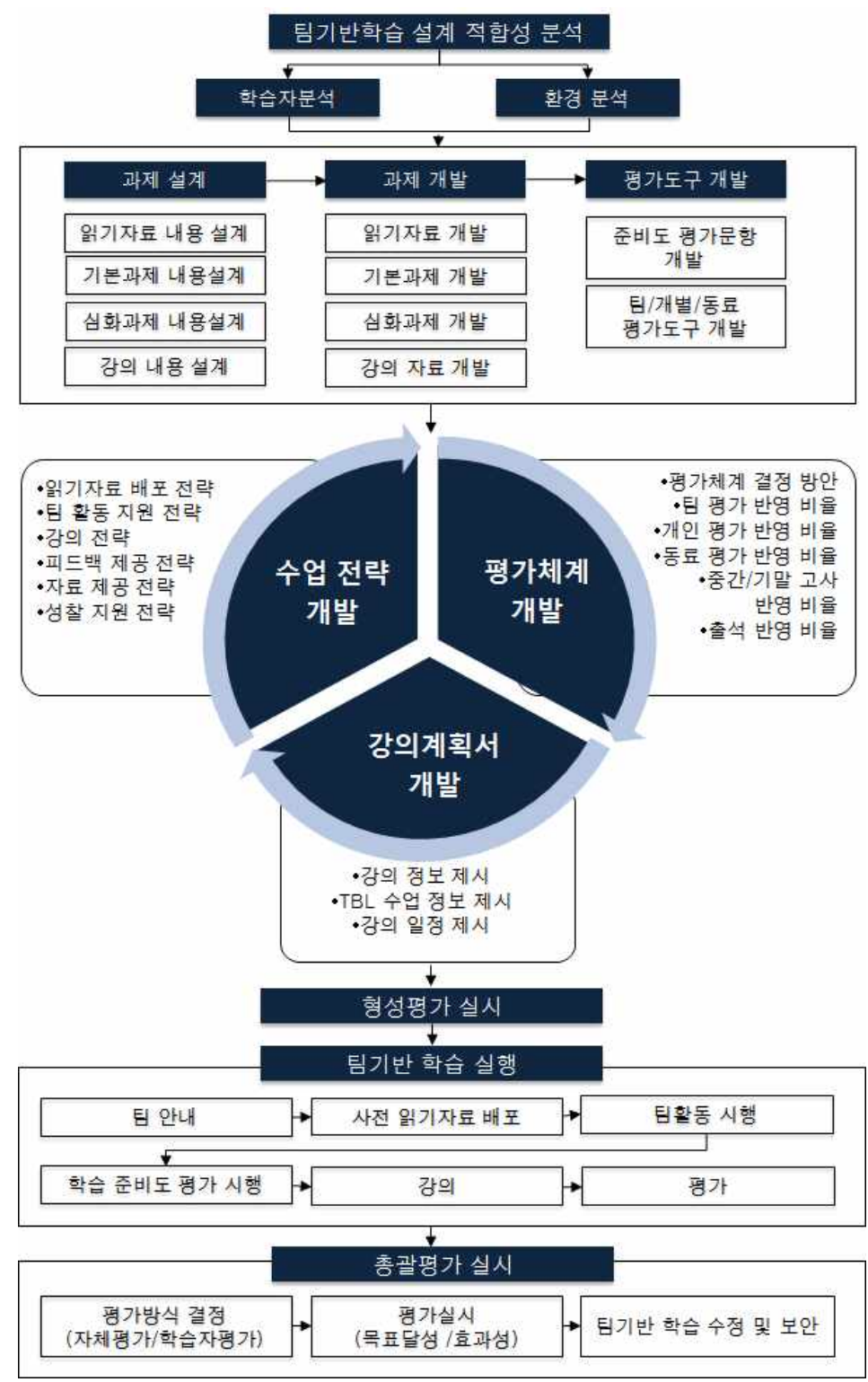

[그림 3] 최종 팀기반 학습 설계모형 
팀기반 학습 설계 적합성 분석 : 팀기반 학습은 팀 활동을 통해 학습자가 단순히 지식의 획득 을 넘어서 지식을 활용하여 심도 있는 학습을 하도록 촉진하고 고차원적 사고 능력을 기르도록 하며, 팀원 전체가 같은 관점에서 높은 학습 성과를 얻도록 하는 것을 목표로 한다(Michaelson \& Sweet, 2008a). 본 단계에서는 설계하고자 하는 강좌의 목표를 달성하기 위해 팀기반 학습이 적합한지 여부를 파악한다. 즉, 교수자가 정한 학습 목표에 따라 팀기반 학습의 적용여부를 결정 해야 한다. 예를 들어 같은 미적분 수업을 진행하더라도 수업목표가 미분 계산 능력을 기르는 것인지, 미분 지식을 이용한 문제 해결을 통해 논리력을 향상시키는 것인지에 따라 팀 기반 학습 의 적합성 여부가 달라진다.

학습자 분석 : 팀기반 학습에서 가장 핵심이 되는 요소 중 하나는 팀 구성 방식이다. 효과적인 팀 구성을 위해서는 학습자의 특성을 파악하는 것이 중요하다. 학습자의 기본 정보(전공, 학년, 나이, 성별 등), 학습자의 배경(강좌 수강 이유, 소속 동아리 등), 학습자의 선행 지식수준, 흥미, 학습 능력, 학습자의 성향(외향적, 내향적), 학습자의 학습 스타일(개별학습 선호, 팀 학습 선호 등) 등 팀 구성에 있어서 고려해야 할 다양한 특징들을 분석한다. 우리나라 대학의 경우, 일반적 으로 학습자들이 수강을 신청하는 기간 전에 강의계획서를 입력해야 하고 그 후에 강의 신청이 이루어지므로 강좌를 설계하기 전에 학습자 분석을 실시하기란 현실적으로 어려움이 있다. 따라 서 이러한 불편한 점에 대한 보완책으로 이 강의를 수강하게 될 예비학습자들과 비슷한 학습자 들을 사전에 분석하는 방안과 수강신청 기간에 강좌를 신청한 학습자들의 일부를 대상으로 학 습자 분석을 하는 방안이 있을 수 있다. 또는 실제로 수업을 수강하는 학습자 분석을 위해 강의 첫 주에 설문조사를 실시하는 형태로 수행될 수 있다. 본 강의와 관련된 학생들의 지식수준을 고려하여 분석하기 위해서는 해당 강의와 관련된 공인인증 성적이나 해당 강의와 관련된 다른 강의의 선행 수강 여부, 해당 강의를 하는 강사의 다른 수업의 수강 여부 등을 중점적으로 살펴 볼 수 있다.

팀기반 학습에서 팀을 구성할 때는 팀 내부의 팀원들 간은 이질적으로 구성하고, 팀 간은 동질 적 특성을 가진 집단으로 구성하는 것이 효과적이다. 따라서 학습자분석 단계에서 개발한 설문 문항 중 팀 형성에 가장 고려해야 하는 점을 중점적으로 다루어 팀을 구성한다. 고려해야 하는 사항에는 학습 수준, 선행 학습 정도, 해당 과목에 대한 흥미도 등등을 예로 들 수 있다. 만약 신입생들을 대상으로 하는 강좌일 경우, 같은 동아리, 같은 학교 출신 간에 하위 집단을 구성 할 우려가 있으므로 이 점을 고려하여 같은 조에 배치하지 않도록 해야 한다. 예를 들어 영어 회화의 과목일 경우, 유학 경험이 있거나 회화 능력에 대한 공인 인증 성적 같은 것을 소지하고 있는 학생들은 절대로 같은 조에 배치되어서는 안 된다. 최대한 영어 능력이 좋은 학생들이 팀 간에 고르게 배치되어 팀 끼리 영어 수준은 동일하게 갖추어질 수 있도록 해야 한다. 팀 구성 시에는 분석된 학습자특성을 기반으로 공개된 곳에서 팀을 구성하는 방식을 사용하는 것도 좋다. 
환경분석 : 학습자 분석에서 학습자의 인원이 파악되면 학습이 이루어지는 강의실의 규모가 학습자의 모든 인원을 수용가능한지 파악해야 한다. 또한 강의실 내부에 있는 시설의 점검도 이 루어져야 한다. 대형 강의를 위해서는 컴퓨터와 빔 프로젝터 마이크 등 ICT 기계가 제대로 갖추 어 져야 한다. 이 외에 학습 결과물을 공유할 수 있는 기자재가 있다면 작동 가능한지 점검한다. 팀 활동을 위해서는 책상과 의자가 고정되어 있는 것보다 유동적으로 움직일 수 있는 것이 적합 하다. 강의실의 공간이 책상과 의자를 팀 활동에 맞게 배치할 수 있을 만큼 확보되는지 확인하는 것도 필요하다. 뿐만 아니라 교수자가 자유롭게 이동하며 학생들의 활동에 피드백을 줄 수 있도 록 이동 공간이 확보될 수 있는지 확인해야 한다. 수업의 대부분은 팀 활동으로 이루어지기 때문 에 소음이 발생할 수 있다. 따라서 방음 시설이 충분히 갖추어져 있는지도 확인한다.

환경에 대한 분석이 이루어지면 학습 환경을 설계해야 한다. 가장 먼저 수강인원과 팀의 개수 를 고려하여 팀 활동이 가능하도록 자리를 배치한다. 자리배치 시 고려해야 할 사항은 다음과 같다. 첫째, 수업에 참여가능한 조교의 수를 고려하여 자리배치를 한다. 팀 활동을 위해 팀 별 책상을 원형으로 배치하거나 'ㄷ자형 등으로 배치하여 팀 활동이 원활하게 이루어질 수 있도록 한다. 팀원 간 사이가 너무 멀면 팀 활동이 원활하게 이루어지지 않을 수 있기 때문이다. 둘째, 교수자가 강의실을 돌아다니며 학습자들의 팀 활동을 모니터링 할 수 있도록 자리를 배치한다. 셋째, 학습자들이 자신들이 작성한 학습결과물을 벽이나 화이트보드에 개시할 수 있는 공간을 확보하여 자리를 배치한다. 만약 학습 결과물을 공유할 수 있는 기자재가 지원된다면, 공유를 위해 필요한 소프트웨어나 하드웨어가 작동 가능하도록 설치한다. 넷째, 팀 간의 의견 공유를 위해 대형 강의실에서도 충분히 의견을 전달할 수 있도록 2 개 이상의 무선 마이크를 배치한다. 다섯째, 학습 준비도 평가지, 동료 평가지, 팀별 과제 등을 섞이지 않도록 수거하여 정리할 수 있는 파일이나 폴더를 준비한다. 여섯째, 팀 별 활동을 위해 필요한 필기도구나 문구류가 있다면 사전에 준비한다.

과제설계 : 과제설계는 학습자가 수업에서 학습활동을 위한 자료들을 설계하는 활동이다. 먼 저 교수자는 기존의 교육과정을 충분히 인지한 후, 한 학기동안 다루고자 하는 내용을 크게 4 에 서 7개의 대단위로 분할한다. 그리고 분할된 내용을 고려하여 각 단위의 수업의 학습목표를 명 확히 하는 활동이 요구된다. 이를 위해 교수자는 학습자가 새로 습득한 지식을 기반으로 어떤 활동을 수행해야 하는지를 고려해야 한다. 마지막으로 선정된 학습 목표에 도달하기 위해 각 수 업에서 학습자가 배워야 하는 내용을 분석하여 팀기반 학습에 필요한 자료들의 내용과 난이도 를 결정한다. 팀기반 학습을 진행하기 위해서는 읽기자료, 기본 과제, 심화 과제 그리고 강의내 용이 필요하다. 따라서 교수자는 수업 내용의 핵심이 되는 내용이 무엇인지 파악하여 읽기자료 가 포함해야 할 내용을 설계한다. 이 읽기 자료의 내용을 바탕으로 팀 활동으로 제공되는 기본 과제와 심화과제가 포함할 내용과 그 난이도를 결정한다. 읽기 자료의 내용과 과제를 고려하여 
학습자들이 간과하기 쉬운 개념이나 학습자들이 어려워할 것으로 예상되는 부분에 대한 강의의 내용을 설계한다.

팀기반 학습의 대부분은 학생들이 중심이 되어 수업이 이루어진다. 학생들은 수업 전에 읽기 자료를 통해 기본적인 지식을 습득하고 본 수업에서는 대부분의 시간을 팀 활동에 할애한다. 따 라서 교수자는 수업에 필요한 기본 내용과 과제 해결 단계에서 학생들이 겪을 수 있는 혼란을 미리 예상하여 강의내용을 설계해야 한다.

과제 개발 : 과제개발은 크게 읽기자료, 기본 과제, 심화 과제로 구분된다. 먼저읽기자료 개발 내용은 다음과 같다. 수업의 각 차시마다 학생들이 학습할 내용들이 결정되면 학습을 위해 학생 들이 반드시 이해해야 하는 개념, 이슈, 아이디어들에 대한 정보를 포함하는 읽기자료를 개발한 다. 학생들이 수업의 주제와 관련된 문제를 해결하기 위해 알아야 하는 핵심 정보들이 무엇인지 결정하고 그것들이 포함된 책이나 기사, 보고서를 찾아 제시하거나 교수자가 자체적으로 읽기 자료를 제작하여 제시할 수도 있다. 여기서 중요하게 고려될 사항은 반드시 팀 내에서 활동할 과제 해결을 위해 꼭 필요한 지식이 빠짐없이 제시되어 있어야 한다는 것과 학습자가 이해할 수 있을 만한 수준의 것이어야 한다는 것이다. 읽기 자료의 수준이 너무 어려우면 학습자는 수업 전에 읽기 자료를 이해하지 못하게 될 수 있으며, 따라서 과제 해결을 위한 지식을 갖지 못한 채로 팀 활동에 참가하게 될 수 있다. 또 읽기 자료의 수준이 너무 쉬운 경우에는 학습자에게는 개별 학습을 통해 스스로 사고할 기회가 줄어들 수 있고 또는 그 자료가 팀 활동에서 제시되는 과제의 해결을 위한 충분한 지식이 제공되지 않은 자료일 가능성이 높다. 읽기 자료의 수준이 적절하다 할지라도 읽기 자료의 양이 너무 많으면 학습자들은 오히려 수업 준비를 하지 않을 가능성이 높다. 따라서 읽기 자료를 선정하거나 자체 제작할 때에는 학습자의 수준과 팀 활동으 로 제시할 과제의 수준, 그리고 읽어야 할 자료의 양을 충분히 고려하여 설정해야 한다. 또한 학습자들은 제시된 읽기 자료로 사전 수업준비를 할 때 무엇이 핵심 내용이고, 앞으로 진행 될 수업 내에서 팀 활동 시 필요한 내용이 무엇인 지, 어떤 내용을 다루게 될지 판단하는 데 어려움 을 겪을 수도 있다. 따라서 학생들이 사전 수업 준비를 할 때에 학생들에게 읽기 지침 자료를 함께 제시하거나, 핵심 내용을 유도할 수 있는 유도 질문을 포함시켜서 핵심 내용을 중심으로 학습할 수 있도록 해야 한다. 이러한 안내를 통해서 성실히 준비해 온 학습자들은 모두 제대로 팀 활동에 참여할 수 있도록 해야 한다.

읽기자료가 완성되면 기본과제가 개발되어야 한다. 기본 과제는 너무 단순하지 않되 팀 내부 의 적절한 토론을 이끌 수 있는 낮은 수준의 응용문제라고 볼 수 있다. 팀기반 학습에서 팀 활동 의 궁극적인 목표는 실제적 과제 해결이다. 실제 상황에서 충분히 일어날 법한 과제를 가상으로 만들어 해결하는 활동을 하는 것이다. 기본 과제 해결은 실제적 과제 해결 전에 준비 단계로써 행해지는 팀 활동이라고 볼 수 있다. 따라서 기본 과제는 실제 상황과 비슷한 과제이기보다는 
기본 개념을 약간 응용하여 해결할 수 있는 수준으로 개발해야 한다. 동시에 실제적 과제 해결을 준비하기 위해 필요한 해결 방법의 일부분을 사용할 수 있는 과제여야 한다.

심화 과제는 읽기 자료와 기본 과제 해결을 통해 학습된 지식과 학습자의 충분한 이해를 바 탕으로 팀 내부의 토론으로 해결할 수 있는 충분히 난이도 있는 과제여야 한다. 심화 과제는 기 본 과제보다 한 단계 더 응용되고 실제 상황에서 충분히 접할 수 있을 법한 과제로 제시된다. 그렇기 때문에 과제는 단순히 개념을 기술하거나 공식을 활용해 푸는 과제들과 달리 실제 접할 수 있는 상황과 인물 조건 등을 자세히 묘사하여 제시된다. 심화 과제는 팀원 간의 적절한 수준 의 토론을 유발할 수 있어야 하며, 과제 해결을 위해 모든 팀원이 참여해야 할 만큼 충분히 복 잡해야 한다. 해결해야하는 과제가 결코 팀원들끼리 나누어서 해결하고 나중에 합칠 수 있는 과 제여서는 안 된다. 반드시 과제의 해결 과정을 처음부터 끝까지 모든 팀원들이 함께하여 최종 결과물을 낼 수 있는 과제여야 한다. 또한 과제 해결 시간도 고려해야 할 요소 중 하나이다. 팀기 반 학습의 장점 중 하나는 수업 외의 시간에 팀별로 따로 모임을 갖지 않는다는 것이다. 따라서 주어진 과제는 수업 시간 안에 해결될 수 있을 만한 수준의 과제여야 한다. 심화 과제는 난이도 가 높기 때문에 학생들이 쉽게 흥미를 잃을 수도 있다. 따라서 과제는 학생들이 복잡한 상황에서 도 그 흥미를 잃지 않도록 학생들의 상황과 밀접한 가상의 상황을 설정하거나 대상 학생들의 연령과 세대를 고려하여 관심을 끌 수 있는 요소들을 활용하는 것도 좋은 방법이다.

마지막으로, 강의자료 개발이다. 학생들은 수업이 진행되는 동안 무엇을 배웠는지 파악하지 못하거나 학습된 내용을 제대로 인지하지 못할 수가 있다. 특히 수업 전 읽기자료를 통해 학생들 은 스스로 학습을 하기 때문에 수업에 핵심이 되는 내용을 스스로 파악하는 데 어려움을 겪기도 한다. 이렇게 설계된 강의 내용을 바탕으로 강의를 위해 필요한 자료를 개발한다.

평가도구 개발 : 읽기 자료를 읽고 학습자는 학습을 사전에 준비하여 강의실로 오게 된다. 학 생들은 사전에 배포된 자료를 얼마나 학습했는지 평가받는다. 이 단계에서는 학생들의 학습 준 비도에 대한 평가 문항을 개발한다. 이 평가 문항은 사전에 배포된 읽기자료의 내용을 바탕으로 학생들이 읽기 자료에서의 핵심 내용을 제대로 이해했는지를 평가할 수 있는 질문들로 구성된 다. 질문들은 읽기 자료의 핵심 내용에 초점을 맞추어 개발되어야 하며, 학생들이 충분히 생각할 기회를 제공하는 문항이어야 한다. 단순한 암기로 해결할 수 있는 문항 보다는 학생들의 이해 정도를 파악할 수 있는 문항으로 개발한다. 이 문항들이 학생들의 학습 동기를 자극할 수 있을 만한 수준의 문항일수록 학생들의 팀 활동의 개입을 촉진시킬 수 있다.

준비도 평가 문항이 개발되면 교수자 평가 도구와 동료평가 도구가 개발되어야 한다. 교수자 평가도구는 모든 학습활동이 끝난 후 교수자의 입장에서 개인별, 팀별 성과를 평가하는 도구를 의미한다. 팀기반 학습의 최종 목표는 학생들이 팀 활동을 통해 토론하며 사고하게 하여 고차원 적 사고력을 증진시키는 것이다. 따라서 교수자는 팀기반 학습의 최종 목표를 기준으로 학생들 
의 개별 성과와 팀 성과를 평가할 수 있는 도구를 개발한다. 개별성과 평가를 위해서는 학생들이 얼마나 많은 지식을 배웠는지 판단할 수 있는 단순 지식 평가문항과 지식을 활용해서 해결할 수 있는 내용 이해도 평가 문항을 개발한다. 또 팀 성과를 평가하기 위해서는 팀별 활동을 통해 도출된 최종 결과물을 평가한다. 사전 지식을 사용하여 적절한 의사 결정을 통해 과제를 해결하 였는지를 최종 결과물로 판단할 수 있도록 적절한 준거를 개발하여 평가한다. 평가 도구는 종이 로 제시할 것인지, 포털 사이트를 통해 제시할 것인지 결정하여 개발한다.

동료평가 도구의 경우, 동료평가체계 설계 단계의 내용을 중심으로 기여도, 배려도, 준비도, 융통성을 잘 반영한 실제 동료평가도구를 개발한다. 동료평가 도구는 준비도(수업 준비는 얼마 나 하였는가?), 기여도(집단 토론과 성과에 얼마나 기여하였는가?), 배려도(다른 동료가 아이디 어를 제시하도록 지지하였는가?), 융통성(의견 불일치가 나타났을 때 유연하게 반응하였는가?) 등을 고려하여 동료평가를 할 수 있도록 개발할 수 있다.

수업 전략 개발 : 과제분석과 학습자분석 결과를 바탕으로 한 학기 전체 수업을 팀기반 학습 으로 운영할 것인지 아니면 몇 가지 주제에 대해서만 팀기반 학습으로 운영할 것인지를 결정한 다. 일주일에 2시간으로 운영되는 강좌의 경우, 시간이 부족할 수 있다는 점을 고려하여, 온라인 수업과 병행하는 방안, 또는 학습자 분석 후 가능하다면 일주일에 3시간으로 강의시간을 변경하 는 방안 등이 모색되어야 한다. 또한 강의의 처음과 끝을 계획적으로 설계하는 것이 중요하다. 1,2 차시를 팀기반 학습 소개를 위해 할애하여 학습자들의 사전 정보 획득과 학습자들이 팀기반 학습 방식과 절차를 이해할 수 있도록 구성한다. 강의 첫날에는 먼저 강의 계획서를 배부하고 팀기반 학습 절차에 대한 개론 소개 및 학습자 사전 정보 획득을 위한 설문시간도 확보하여야 한다. 또한 학습자들이 가장 예민할 수 있는 평가 체계를 학생들이 충분히 동의할 수 있을 만큼 의견을 모아 결정해야 한다. 교수자는 수업 전 미리 평가 체계를 설계한다. 교수자는 학습자들에 게 미리 설계된 평가체계를 설명하고 각 평가 항목 당 일정 한도를 제안한다. 이 범위 안에서 학생들이 충분히 평가체계를 수정할 수 있도록 논의한다. 학습자 분석을 강의 첫 날 하는 경우에 는 팀 구성 및 강의계획서 최종 확정을 위한 학습자 분석을 설문형태로 실시해야 한다. 학습자 분석 도구는 앞서 학습자 분석 단계에서 제시된 양식을 참고하여 교수자가 수정·보완하여 사용 할 수 있다. 강의 2 번째 주에는 팀 배정 결과를 발표한 뒤 팀 별로 자리를 배치하고 팀원 간 아이 스 브레이킹이 이루어질 수 있도록 촉진자의 역할을 수행해야 한다.

2차시 이후로 본격적인 내용 수업을 시작하게 되면 교수자들은 매 수업시간 전에 읽기자료를 배포해야 한다. 교수자들은 학생들이 수업 전에 사전 읽기 자료를 완전히 읽고 충분히 이해할 수 있을 만큼 적절한 시간을 제공해야 한다. 본 수업을 시작하면 가장 먼저 학생들이 읽기 자료 를 충분히 학습하고 수업에 들어왔는지 확인하기 위해 사전 준비도 평가를 실시한다. 사전 준비 도 평가는 개인 사전 준비도와 팀별 사전 준비도 평가를 각각 진행한다. 개인별 사전 준비도 평 
가 후 팀 별로 모여서 서로의 의견을 교환하며 팀별 사전 준비도 평가를 실행한다. 사전 준비도 평가 후 읽기 자료에 대한 이해도가 떨어지는 부분이 있다면 교수자는 간략하게 그 내용에 대한 강의를 진행함으로써 학습자들이 충분한 이해를 바탕으로 팀 활동을 진행할 수 있도록 도움을 줄 수 있다.

사전 준비도 평가가 끝나면 본격적인 팀 활동을 시작하게 된다. 이 때 모든 팀들이 그 팀원들 의 참여를 촉진시킬 수 있는 구조가 되도록 배치해야 한다. 강의실이 재배치되면 팀 활동을 위한 과제를 제시한다. 과제는 기본 과제에서 심화 과제 순서로 제시된다. 교수자는 교실 내부를 돌아 다니며 팀들의 팀 활동을 파악하여 토론 내용이 바른 곳으로 흘러갈 수 있도록 적절하게 안내해 야 한다. 교수자는 이런 팀에게 충분한 지지와 격려를 주어 팀 활동을 지속적으로 촉진시켜 주 어야 한다. 충분한 팀 활동 시간을 주었음에도 불구하고 활동에 몰입하여 배분된 시간 내에 마 무리 짓지 못하는 경우가 많다. 따라서 이러한 문제를 방지하기 위해 교수자는 주기적으로 학생 들에게 시간을 체크해주어야 한다.

팀 활동이 끝나면 교수자는 학생들이 학습한 내용을 다시 한 번 정리할 수 있도록 짧은 강의 를 한다. 강의와 함께 팀 활동에서 제시된 과제에 대한 다양한 접근 방법과 해결책에 대한 피드 백을 제시한다. 팀 활동 후 산출된 최종 결과물을 공유할 때 교수자는 자신이 세운 준거에 따라 공정하게 평가할 수 있어야 하며, 최종 결과물에 대한 적절한 피드백도 매우 중요하다. 만약 해 당 강의가 중간고사나 기말고사가 있다면, 교수자들은 학생들에게 복습을 위해 핵심 내용을 포 함한 자료를 제시할 수 있다.

모든 수업 일정이 끝난 후 마지막 차시에는 전체 강의에 대한 성찰의 기회를 제공하여 학습내 용은 물론 팀 활동에 대한 이해를 높일 수 있는 전략도 수립되어야 한다. 학습자들이 성찰을 할 때 크게 4가지 측면에서 성찰할 수 있도록 전략을 수립해야 한다(Michaelsen et al., 2009). 첫째, 학습 내용 이해도의 측면에서는 학습 내용을 포괄하는 목록을 제시한 후 명확히 이해하지 못한 부분을 기술하고 팀원끼리 공유하며 서로의 내용을 보완할 수 있도록 한다. 둘째, 학습내용의 적용과 이해의 측면에서는 학습 내용을 포괄적으로 이해하고 적용할 수 있는 사례를 제시하여 팀 별로 해결방안을 도출할 수 있도록 한다. 셋째, 팀 활동의 가치에 대한 학습 측면에서는 한 학기동안 획득한 개인 점수, 평균 점수, 최저 점수, 팀별 점수와 개인 최고점수의 차이 등을 그래 프로 나타내어 팀 활동의 가치를 객관적으로 확인할 수 있도록 한다. 넷째, 팀의 효과적인 상호 작용에 대한 인지측면에서는 팀기반 학습 전과 후에 팀 활동에 대한 의견을 작성하도록 하여 변화된 부분이 무엇인지 살펴보고, 그 변화가 생긴 원인들을 작성해서 서로 공유할 수 있도록 전략을 세운다. 팀의 효과성에 좋지 않은 영향을 끼친 요인이 무엇인지 파악하고 극복할 수 있는 방법에 대해 토론하고 작성할 수 있는 수업전략을 세우며, 이러한 성찰 과정을 통해서 학생들은 팀 활동에 대해 다시 한 번 생각함으로써 효과성에 대해 생각해 볼 수 있는 기회를 가질 수 있도 
록 수업전략을 수립한다. 이밖에도 학습자들의 토론 과정과 과제수행 과정을 관찰하고 기록할 수 있는 양식을 개발하는 활동도 필요하다.

평가체제 개발 : 이 단계에서 교수자는 개인성과, 팀 성과, 팀의 성공을 위한 각 팀원들의 공헌 도 등을 고려한 전체 성적체제를 개발한다. 성적체계를 설계하는데 있어서 교수자는 개인의 성 과, 팀성과, 팀의 성공에 대한 팀원들의 기여도를 측정할 수 있도록 평가체계를 개발한다. 소집 단 학습에서 흔히 발생하는 무임승차를 방지하기 위하여 평가체계는 학습자들에게 공지되는 것 이 좋다. 이를 위해 평가 시기와 평가항목, 가중치 등을 학습자들에게 공지할 수 있는 수준으로 개발해야 한다.

강의계획서 개발 : 학생들은 매 차시마다 준비해야 하는 학습 내용과 주제를 숙지하고 있어야 하기 때문에 팀기반 학습의 강의계획서는 다른 보통의 수업에 비해 학생들의 사전 수업 준비를 위해 매우 중요한 역할을 한다.

강의계획서에 포함되어야 할 범주 및 내용은 다음과 같다. 첫째, 기본적인 강의정보가 포함되 어야 한다. 예를 들어, 일반적인 강좌정보(교과명, 강의번호, 학점, 이수조건, 강의실, 시간, 개설 학과 주교재 정보 등)과 교수자 관련 정보(이름, 직위, 연구실 위치 및 전화번호, 개설학과 전화 번호 등), 평가 방식(준비도, 팀, 개별, 동료, 중간, 기말 등)이 여기에 해당된다. 둘째, 팀기반 학 습 오리엔테이션 자료가 포함되어야 한다. 강의의 목적, 학습목표, 평가체계, 수업진행방법, 학습 자와 교수자의 역할, 주요 학습활동 등이 자세히 안내되어야 한다. 셋째, 강의 일정이 매우 정교 하게 구성되어야 한다. 주차별로 강의 주제, 학습목표, 읽기자료 목록 등이 자세히 제시되어야 한다. 강의 일정으로 1,2차시에 팀기반 학습 진행 방식 관련 오리엔테이션 일정을 제시하고, 매 차시마다 사전 읽기자료의 주제를 제시하여 학생들이 해당하는 수업에 맞는 올바른 읽기자료를 읽고 사전 학습을 해올 수 있도록 도움을 주는 계획서로 구성한다.

형성평가 실시 : 형성평가는 팀기반 학습을 처음 도입하는 교수자에게 특히 중요한 단계이다. 최소 3 4명의 학습자와 함께 사전읽기자료 배포, 학습준비도 평가문항의 풀이 및 답안지 회수, 성적체계 등을 실행 해 본다. 팀기반 학습 운영 경험이 있는 교수자는 가상으로 시뮬레이션 해보 거나 이 단계를 생략할 수 있지만, 가능하면 실제 학습자들과 함께 수업을 실행해봄으로써 돌발 사항을 미연에 방지 또는 해결책을 찾아볼 것이 바람직하다. 형성평가 후 학습자들로부터 다음 과 같은 개선점을 도출할 수 있다. 개선점으로는 첫째, 팀기반 학습 설계 적합성 분석, 환경 분 석, 학습자 분석은 팀기반 학습의 특징을 충분히 고려하여 분석하였는지, 둘째, 분석 단계의 결 과가 설계 시 충분히 반영되었는지 셋째, 환경설계, 수업 내용 설계, 팀 구성 시 팀기반 학습에 적합하도록 설계되었는지, 넷째, 평가 문항은 학습자의 목표 달성 여부를 충분히 반영 하였는지, 다섯째, 읽기 자료와 팀 활동 과제는 학습 목표에 적합하게 개발되었는지, 여섯째, 평가도구는 설계된 것을 바탕으로 적절하게 개발되었는지 등이 해당되며, 이에 대한 정보는 모의 수업 실행 
후 학습자들과의 인터뷰 등을 통해 수집될 수 있다.

팀기반학습 실행 : 실행 단계에서는 설계된 모든 수업 절차가 제대로 실행될 수 있도록 빠짐 없이 검토해야 한다. 형성평가로부터 도출된 개선점을 충분히 반영하여 설계된 수업을 수정한 뒤 최종 도출된 수업 설계안을 실제로 실행한다.

총괄평가 실시: 설계된 팀기반 학습의 실행이 종료되면 총괄평가를 실시하여 수업 설계안을 검토한다. 형성평가는 자체평가를 할 수도 있고, 학습자들의 평가를 받을 수도 있다. 교수자 자 체 평가로는 설계된 팀기반 학습을 통해 학습 목표를 달성하였는지, 수업의 효과성이 있다고 생 각하는지, 개선되어야 할 점은 무엇인지, 각 자료들이 팀 학습 활동을 위해 충분한 정보를 담고 있었는지 등의 검토를 통해 설계된 수업 절차를 평가하고 평가 결과를 반영하여 기존의 수업을 수정하고 보완한다. 총괄 평가가 제대로 이루어지기 위해서는 이러한 사항에 대해 객관적으로 판단할 수 있는 준거를 개발하여 평가하는 것이 좋다. 학습자들의 평가는 대학에서는 학기가 끝 날 때 시행하는 강의평가 결과가 좋은 자료가 된다. 학생들이 평가한 강의 평가 내용을 바탕으로 수업 전체를 검토할 수 있다.

\section{V. 논의 및 결론}

본 연구에서의 목적은 일반적인 대학 강의에서 초보 교수설계자들도 효율적으로 팀 기반 학 습을 설계할 수 있도록 안내하는 팀 기반 학습 설계모형을 개발하는데 있다. 이를 위해 기존의 팀 기반 학습관련 문헌들을 탐색하여 팀 기반 학습의 구성요소들을 도출하고, 그것을 바탕으로 최초의 모형을 설계하였다. 그리고 설계된 최초 모형은 4 인의 전문가 검토, 3 인의 사용성 평가를 거쳐 최종 팀 기반 학습 설계모형이 개발되었으며, 그리고 최종 모형은 팀기반 학습 및 교수설계 전문가 7인으로부터 타당화를 검증받았다.

본 연구를 통해 도출된 논의점을 살펴보면 다음과 같다. 첫째, 본 연구를 통해 개발된 모형은 팀기반 학습을 실행하기 위한 교수설계자의 활동이 규명되어 있다. 기존의 팀기반 학습 모형은 준비도 평가 등 수업 전 약간의 활동에 대한 안내와 함께 주로 실제 팀기반 학습을 실행하는데 초점을 두고 있다(조아라, 2008; Haidet et al.2012). 그러나 본 연구에서 개발된 모형은 수업 전, 중, 후에 포함되는 일련의 설계과정을 모두 안내하는 모형이므로 수업을 실행하는데 초점을 둔 팀기반 교수학습 모형보다 포괄적인 모형이라 할 수 있다.

둘째, 본 모형은 대학에서의 팀 기반 학습을 실행하는데 필요한 설계모형이라는 점에서 초,중, 고등학생 또는 특정한 성인집단을 대상으로 이루어지는 팀기반 학습 설계모형과 차별점을 갖는 다. 본 모형에 제시된 평가체제개발 단계에서 중간·기말고사 반영비율 정하는 활동이나 강의계 
획서개발 등의 활동은 대학에서의 교수.학습 맥락을 반영한 교수설계 활동임을 알 수 있다. 따 라서 본 모형은 대학에서 대형 강좌이면서 강좌의 목적이 학습자의 고차원적인 사고능력인 경 우에 본 모형의 매우 효과적이다. 그러나 소규모 강좌일 경우에도 본 연구를 통해 개발된 설계모 형이 충분히 활용될 수 있음을 강조하고자 한다.

셋째, 본 모형에서 과제설계, 과제 개발 및 평가도구 개발 단계가 가장 중요한 부분이라고 할 수 있다. 팀 기반 학습은 다른 수업과는 다르게 학습자 개개인의 준비도 평가로부터 수업이 시작 되며, 팀 과제 역시 난이도가 낮은 과제와 높은 과제가 학습자에게 제시된다. 팀 기반 학습의 평가는 개인성과와 팀 성과 결과 그리고 동료 평가 결과의 총합으로 이루어진다. 즉, 팀 기반 학습에서의 평가는 준비도 결과, 과제해결 결과 등 다양한 결과물을 해결해야 하며, 평가 방식 또한 다양하므로 교수설계자의 세밀한 설계가 필요하다(Michaelsen, \& Knight, \& Fink, 2009). 이에, 본 연구에서 개발된 팀 기반 학습 설계모형에서는 과제 설계 및 개발 및 평가 단계에서 요구되는 교수자의 설계활동을 자세히 진술되었다.

넷째, 본 연구에서 개발한 모형을 더 효율적으로 활용하기 위해서 본 모형을 사용하는 교수설 계자는 모형을 활용하여 팀 기반 학습을 설계할 때 모형의 각 단계별 결과물들을 정리하여 티칭 포트폴리오(teaching portfolio)를 제작하는 것이 좋다. 티칭포트폴리오 작성 통해 교수자는 자신 이 설계한 수업에 대한 실제적인 평가를 심도있게 할 수 있으며(Wolf, 1998), 학습자 중심 교육 의 가능성을 높일 수 있다(Barton, \& Collins, 1993). 따라서 교수설계자가 본 연구에서 개발된 모형을 활용하여 수업을 설계하고 실행하는 과정에서 도출된 결과물을 모아 티칭포트폴리오로 활용하면 앞으로의 팀 기반 학습 활용을 위한 예시 자료로 활용될 수 있어 팀 기반 학습을 시행 하는 데 좀 더 효과적이고 상황이나 맥락에 적합하도록 설계하는 데 도움이 될 수 있다.

본 연구를 통해 개발된 팀 기반 학습 설계모형의 의의를 살펴보면 다음과 같다. 첫째, 팀 기반 학습을 활용함으로써 얻을 수 있는 다양한 학문적, 정서적 성과를 고려하였을 때, 팀 기반 학습 은 앞서 언급된 학문 외에도 더 다양한 학문에 적용될만한 가치가 있다고 보인다. 이러한 맥락에 서 본 연구는 팀 기반 학습이 다양한 분야의 학문에 유용하게 활용되는 데 도움이 될 수 있는 모형을 개발하였다는 점에서 그 의의가 있다고 할 수 있다. 둘째, 기존의 많은 팀 기반 학습 연구 들은 팀 기반 학습을 효율적으로 활용하는 데 도움이 되는 팀 기반 학습의 수업 절차와 내용에 대한 안내를 제공하고 있다. 본 연구는 이러한 내용들을 토대로 교수자가 팀 기반 학습을 설계하 기 위해 거쳐야 하는 정확한 단계와 각 단계별 상황적 지침을 자세히 제공하고, 그것을 시각화하 였다는 점에서 기존의 연구와는 구별된다고 할 수 있다. 본 연구의 결과는 수업 설계에 서툰 초 보자도 손쉽게 팀 기반 학습을 설계할 수 있도록 보기 쉽고 자세하게 팀 기반 학습 설계 절차를 제시했다는 점에서 교수자들에게 많은 도움이 될 것이라고 기대한다.

마지막으로 본 연구를 통해 개발한 팀 기반 학습 설계모형에 대한 제한점 및 추후 연구를 살 
펴보면 다음과 같다. 첫째, 본 팀 기반 학습 설계모형은 전문가 검토, 사용성 평가, 전문가 타당 화 등 여러 차례에 걸쳐 비교적 엄격하게 검증을 받으며 완성되었다. 그러나 모형 타당화의 또 다른 방법으로써 모형의 효과성을 검증하는 연구가 수행될 필요가 있다. 실제 본 모형으로 설계 된 수업을 실행한 후 학습자들의 학업성취도 및 고차원적인 사고능력, 팀워크 능력 등을 측정하 여 통제집단의 결과와 비교하는 연구가 필요하다.

둘째, 팀 기반 학습은 그 절차와 과정이 매우 복잡하므로 팀 기반 학습을 설계하기 위한 활동 또한 매우 까다롭다. 이러한 특성 때문에 본 연구에서 개발된 팀 기반 학습 설계모형 역시 다른 설계모형에 비해 설계활동이 다소 많이 포함되어 있다. 따라서 모형 사용자들이 본 모형대로 수업을 설계할 경우 다소 많은 시간과 노력이 소요될 수 있으며, 이는 곧 모형이 활발히 사용되 지 않을 가능성도 포함하고 있다고 해석될 수 있다. 따라서 이러한 장애요소를 극복할 수 있는 모형 사용 전략에 대해서 추후 연구가 필요하다. 한 예로, 팀 기반 학습의 핵심이 될 수 있는 사항들을 추출하여 안내하는 모형 개발 연구를 들 수 있다.

셋째, 본 연구는 팀 기반 학습 설계모형은 면대면 수업에서 일정 기간 동안 팀 기반 학습을 실행한다는 전제를 기반으로 개발되었다. 따라서 수업의 전 과정에서 이론 학습과 팀 기반 학습 이 함께 존재하는 혼합형 팀 기반 수업이나 한 차시의 수업의 부분으로 팀 기반 학습을 활용하 는 부분형 팀 기반 학습에 대한 수업 설계전략이 포함된 모형 개발 연구가 필요하다. 뿐만 아니 라, 다양한 팀 기반 학습 활동 유형(혼합형, 부분형)을 위한 수업 전략과 상황적 지침을 포함하여 모형을 정교화 시키는 연구가 필요 하다.

마지막으로 팀 기반 학습은 의대에서 시작한 학습 방법으로 그 효과성은 이미 여러 차례 많은 연구에서 검증되었다. 이러한 효과들을 고려했을 때 팀 기반 학습은 대학생뿐 아니라 초, 중, 고 등학교의 학생들을 대상으로 하는 수업에도 그 활용 가능성은 열려있다고 볼 수 있다. 따라서 현재의 초, 중, 고등학교의 교육과정과 학습 환경, 교육 요구들을 고려하여 초, 중, 고등학교 학생 들을 대상으로 하는 팀 기반 학습 설계모형을 개발할 필요가 있다. 


\section{참고문헌}

강정찬(2009). 비계설정을 위한 블렌디드 수업설계모형 개발 - 설계 기반 연구를 적용하여 -. 박사학위논문, 부산대학교. 미간행.

김은경, 조주은, 정의철(2009). 대형 강의에서 교수-학습자 간 커뮤니케이션 활성화에 대한 방안 연구. 한국디자인포럼, 22, 225-234.

나일주, 정현미(2001). 웹기반 가상교육 프로그램 설계를 위한 활동모형 개발. 교육공학연구, $17(2), 27-52$.

나지현, 정현미(2012) 대학수업을 위한 문제중심학습(PBL) 설계모형 개발. 열린교육연구, 20(3), 111-140.

노영숙, 류언나, 최동원, 백선숙, 김상숙(2012). 간호교육에서 TBL의 적용에 관한 연구. 한국간호 교육학회지, 18(2), 239-247.

박귀화, 최창휴, 전양빈, 박국양, 박철현(2012). 일개 의과대학 학생들의 개인적 특성에 따른 팀 바탕학습 인식도 조사. 한국의학교육학회, 25(2), 113-122(질문)

박수홍(2007). 대학교육 혁신에 대한 체제적 사고:학습 프로세스를 중심으로. 교육사상연구, 19, 1-16.

박인숙, 김동기(2009). 치위생 교육과정의 치면세마 교육에 대한 팀기반학습(team-based learning)의 효과. 대한구강보건학회지, 33(1), 125-133.

유병민, 허균(2004). 대학의 대형 강의 현황과 정책적 개선방안: A 대학교 사례 중심으로. 교육정 보미디어연구, 10(4), 141-163.

심미자(2009). 팀기반학습(Team-Based Learning) 전략. 교육공학, 16(3), 57-60.

이수영(2013). 스마트 테크놀로지를 활용한 팀기반 학습 모형 설계 연구. 한국정보교육학회, 17(4), 497-506.

이영민, 남정권, 조형정, 이수영(2011a). 전문계 고등학교에서 팀기반 학습방법이 학습자의 과제 수행, 학습활동, 동기에 미치는 영향. 직업교육학회, 30(2), 51-71.

이영민, 남정권, 조형정, 이수영(2011b). 공업계 고등학교 수업에서 팀기반 학습모형 적용에 관한 형성적 연구. 대한공업교육학회지, 36(2), 1-23.

임철일, 김성욱, 최소영, 김선희(2013). 문화다양성 교육을 위한 지속적 성찰 중심 교수설계 모형 개발 연구. 교육공학연구, 29(4), 751-781.

조아라(2008). 의학교육에서의 효과적인 팀 바탕학습 운영을 위한 팁. 한국의학교육, 20(4), $373-374$. 
조아라(2010). 의학교육에서의 효과적인 팀 바탕학습 운영 방안 및 기대효과. 석사학위논문, 카 톨릭대학교. 미간행.

조형정, 이영민(2008). 학습과정과 성과개선을 위한 팀기반 학습의 개념적 탐색. 교육종합연구, $6(2), 27-42$.

진성희(2009). 구조 이해 및 내용 이해 증진을 위한 디지털텍스트의 시각적 변형 연구. 박사학위 논문, 서울대학교. 미간행.

하채연, 이수영(2014). 초등 과학 수업에서 팀기반 학습모형이 학업 성취도와 정서지능에 미치는 효과. 교육정보미디어연구, 20(1), 1-26.

한국대학교육협의회 (2013). 대학정보공시센터 2013년 10월 보도자료.

http://www. academyinfo.go.kr (2014. 7. 20)

한수정(2013). 간호대학생에 팀기반 학습 적용의 효과. 한국디지털정책학회, 11(11), 595-602. 한혜승, 이란, 손인숙, 이종민, 이경영(2007). 피부병리 의학교육에서 팀바탕학습법 도입에 따른 학생들의 학업성취도와 학생인식 조사. 한국의학교육, 19(3), 257-263.

허희옥, 임규연, 서정희, 김영애(2011). 21세기 학습자 및 교수자 역량 모델링. 한국교육학술정 보원.

황철일, 이성호(2011). 대학 강의식 수업에서 학습자가 경험한 질문 저해요소 분석 연구. 교육과 학연구, 42(1), 181-212.

Andersen, E. A., Strumpel, C., Fensom, I., \& Andrews, W. (2011). Implementing team based learning in large classes: Nurse educators' experiences. International journal of nursing education scholarship, $8(1), 1-16$.

Barton, J., \& Collins, A. (1993). Portfolios in teacher education. Journal of Teacher Education, 44(3), 200-211.

Boud, D., \& Falchikov, N. (2006). Aligning assessment with longterm learning. Assessment \& Evaluation in Higher Education, 31(4), 399-413.

Chin, C., \& Chia, L. G. (2004). Problem-based learning: Using students' questions to drive knowledge construction. Science Education, 88(5), 707-727.

Clair, K. S., \& Chihara, L. (2012). Team-based learning in a statistical literacy class. Journal of Statistics Education, 20(1), 1-20.

Cuseo, J. (2007). The empirical case against large class size: adverse effects on the teaching, learning, and retention of first-year students. The Journal of Faculty Development, 21(1), 5-21.

Dana, S. W. (2007). Implementing team-based learning in an introduction to law course. Journal of Legal Studies Education, 24(1), 59-108. 
Fujikura, T., Takeshita, T., Homma, H., Adachi, K., Miyake, K., Kudo, M., \& Hirakawa, K. (2013). Team-based learning using an audience response system: a possible new strategy for interactive medical education. J Nippon Med Sch, 80(1), 63-69.

Haidet, P., Levine, R. E., Parmelee, D. X., Crow, S., Kennedy, F., Kelly, P. A., Perkowski, L. Michaelsen, L., \& Richards, B. F. (2012). Perspective: Guidelines for reporting team-based learning activities in the medical and health sciences education literature. Academic Medicine, 87(3), 292-299.

Hrynchak, P., \& Batty, H. (2012). The educational theory basis of team-based learning. Medical teacher, 34(10), 796-801.

Jang, S. (2011). An instructional support system design model for ill-structured problem-solving in online learning. Unpublished doctoral dissertation, Seoul National University, Seoul. Lesh, R., \& Doerr, H. M. (2003). Foundations of a models and modeling perspective on mathematics teaching, learning, and problem solving. In R. Lesh \& H. M. Doerr (Eds.), Beyond constructivism Models and modeling perspectives on mathematics teaching, learning, and problem solving. Mahwah, NJ:Lawrence Erlbaum Associates,Inc.

Loo, J. L. (2013). Guided and Team-Based Learning for Chemical Information Literacy. The Journal of Academic Librarianship, 39(3), 252-259.

McInerney, M. J., \& Fink, L. D. (2003). Team-based learning enhances long-term retention and critical thinking in an undergraduate microbial physiology course. Microbiology Education, 4, 3-12.

Mennenga, H. A., \& Smyer, T. (2010). A model for easily incorporating team-based learning into nursing education. International journal of nursing education scholarship, 71), 1-14. Michaelsen L. K., \& Richards, B. D. (2005). Drawing conclusions from the team learning literaturein health-sciences education: A commentary. Teach Learn Med, 17, 85-88.

Michaelsen, L. K., Knight, A. B., \& Fink, L. D. (2009). 팀기반 학습. (이영민, 전도근 옮김). 서울: 학지사. (원서출판 2002).

Michaelsen, L. K., \& Sweet, M. (2008a). The essential elements of teambased learning. New directions for teaching and learning, 2008(116), 7-27.

Michaelsen, L. K., \& Sweet, M. (2008b). Fundamental principles and practices of team-based learning. Team-based learning for health professions education: A guide to using small groups for improving learning(pp. 9-31). Sterling (VA): Stylus Publishing, LLC.

Ndebele, C., \& Maphosa, C. (2013). Exploring the Assessment Terrain in Higher Education: Possibilities and Threats: A Concept Paper. Journal of Social Sciences, 35(2), 149-158. 
Parmelee, D. X., \& Michaelsen, L. K. (2010). Twelve tips for doing effective Team-Based Learning (TBL). Medical teacher, 32(2), 118-122.

Parmelee, D., Michaelsen, L. K., Cook, S., \& Hudes, P. D. (2012). Team-based learning: A practical guide: AMEE Guide No. 65. Medical teacher, 34(5), e275-e287.

Pogge, E. (2013). A Team-Based Learning Course on Nutrition and Lifestyle Modification. American journal of pharmaceutical education, 775), 1-6.

Richey, R. C. (1997). Research on instructional development. Educational Technology Research and Development, 45(3), 91-100.

Richey, R. C. (2005). Validating instructional design and development models. In J. M. Spector, \& D. A. Wiley(Eds.), Innovations in instructional technology: Essays in honor of M. David Merrill(pp. 171-185). NJ: Lawrence Erlbaum Associates, Inc.

Richey, R., \& Klein, J. D. (2007). Design and development research Methods, strategies, and issues. NJ: Routledge.

Rubio, D. M., Berg-Weger, M., Tebb, S. S., Lee, E. S., \& Rauch, S. (2003). Objectifying content validity: Conducting a content validity study in social work research. Social Work Research, 272), 94-104.

Snowball, J. D., \& Boughey, C. (2012). Understanding student performance in a large class. Innovations in Education and Teaching International, 49(2), 195-205.

Trilling, B., \& Fadel, C. (2009). 21st century skills: Learning for life in our times. CA: San Francisco, John Wiley \& Sons.

Weiner H, Plass H, Marz R.(2009). Team-based learning in intensive course format for first year medical students. Croat Med Journal, 50(1), 69-76.

Widen-Wulff, G., \& Ginman, M. (2004). Explaining knowledge sharing in organizations through the dimensions of social capital. Journal of Information Science, 30(5), 448-458.

Wisely, F. G. (1994). Communication Model. In D. M. Moore \& F. M. Dwyer (Eds.), Visual literacy: a spectrum of visual learning. New Jersey: Englewood Cliffs.

Wiener, H., Plass, H., \& Marz, R. (2009). Team-based learning in intensive course format for first-year medical students. Croatian medical journal, 50(1), 69-76.

Wolf, D. P. (1998). Portfolio assessment: Sampling student work. Educational Leadership, 46(7), 35-39. 
* 논문접수 2014년 8월 4일 / 1차 심사 2014년 9월 11일 / 2차 심사 2015년 3월 2일 / 게재승인 2015년 3월 6일

* 장선영: 춘천교육대학교 영어교육과를 졸업하고, 서울대학교 교육학과에서 교육공학 전공으로 석사 - 박사학위를 취득하였다. 현재 청강문화산업대학교 유아교육과 교수로 재직중이다.

*E-mail: syjang6l21@gmail.com

* 이정주: 숭실대학교 통계학과를 졸업하고 중앙대학교 대학원 교육학과 교육공학 석사과정에 재학 중이다.

*E-mail: wanteun@naver.com 


\section{Abstract}

\section{Development of a Team-Based Learning Design Model in Higher Education}

Jang, Seon-young*

Lee, Jeongju*

The purpose of this study is to develop and validate a Team-based learning(TBL) design model in higher education. The TBL design model was developed through the following procedures; 1) developing the 1st TBL design model in higher education based on the results of literature review, 2) getting the expert review on the first TBL design model, 3) getting test for use by four practicing instructional designers, and 4) getting model validation by seven experts.

The developed TBL design model consists of 'judgement of appropriateness of TBL in university class', 'learner analysis', 'team building', 'learning-environment analysis', 'learning -environment design', 'task design', 'task development', 'evaluation tool development', 'formative evaluation', 'TBL instructional strategies design', 'evaluation-system determination', 'syllabus development', TBL implementation', and 'summative evaluation'. The TBL design model in higher education, as a result of this study, includes specific guideline of each step of this model.

The model was validated by seven experts. The results as follows: All of the CVI were over 0.8 , and IRA was near 0.9. These results confirm that the TBL design model was both reliable and valid. The suggested model in this study is expected to be used to design scaffoldings in online learning environments.

Key words: Team-based learning, Design model, model development, higher education

* Corresponding author, Chungkang college of cultural industries, Professor

** Chung-Ang University, Master's Student 